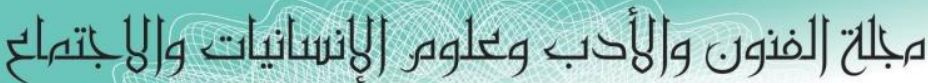
Journal of Arts, Literature, Humanities and Social Sciences

ISSN online: 2414 - 3383

ISSN print: 2616 - 3810

2019 نوفهبر Volume (45)
(45) (40) November 2019
¿ALLHSS www.jalhss.com

\title{
الهوية الثقافية والاجتماعية في المسكن الكوردي المعاصر
}

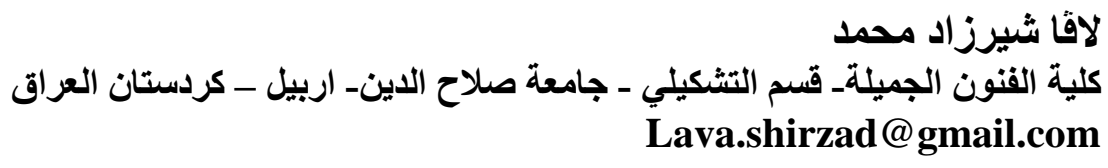

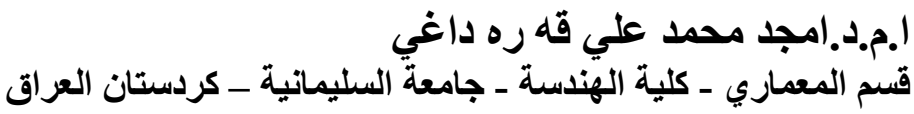

amjad.ali@univsul.edu.iq

الملخص

يهدف البحث الحالي الى تسليط الضوء على محور اساسي الاو هو تحقيق استدامة الهوية الثقافية والاجتماعية للمساكن الكوردية المعاصرة في مدينة اربيل و التي تعكس تاثير الموروث الحضاري للمجتمع الكوردي. كما وتعكس المعاصرة في اسلوب نوزيع العناصر والاسس التصميمية وكذلك نوزيع الفضاءات ونوعية الاثاث و الخامات المستخدمة. وقد تناول البحث في اطاره النظري الهوية الثقافية والاجتماعية، الاستدامة، والتصميم الداخلي و عناصره و اليات استدامته. وقد توصل البحث الى عدد من النتائج ابرز ها ان المجتمع الكوردي قد نوجه في تصميماته للمساكن الكوردية الى ثلاث توجهات منها ماهو معاصر مناثر بالتصاميم الغربية ومنها ما هو متاثر بالتراث وباستخدام العناصر التصميمية التي توحي بالاصلة والفخامة من خلال الخامات والالوان ذات العلاقة بالطبيعة المحيطة، ومن المساكن ماهي ذاتية الاختبار او فردية في تصميمها الداخلي يعتمد على انتقاء الفرد الكوردي لتصميمات وخامات خاصة مناثرا بكلا التوجهين المعاصر والتر اثي. وخلص البحث باستتناجات مستمدة من الاطار النظري حيث شكلت الهوية الثقافية والاجتماعية حضورا لافتا في اغلب التصميمات الداخلية و اسلوب توزيع العناصر بالاعتماد على الموروث ومواكبة التصاميم المعاصرة ولهذا نجد الخصوصية الثقافية و هي ماز الت حاضرة ومتجذرة في المسكن الكوردي. 


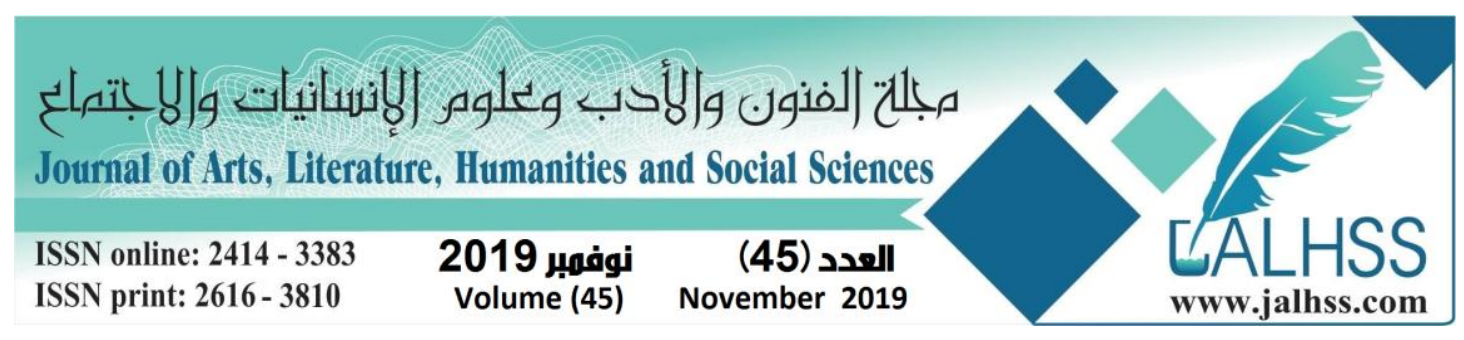

\title{
Cultural and Social Identity in the Modern Kurdish House
}

\author{
Lava Shirzad Muhammed \\ College of Fine Arts- Plastic Arts Department - Salahaddin University-Erbil - \\ Iraqi Kurdistan Region
}

\author{
Assist. Prof. Dr. Amjad M. A. Qaradaghi \\ College of Engineering - Sulaimaniya University - Iraqi Kurdistan Region \\ amjad.ali@univsul.edu.iq
}

\begin{abstract}
The present research aims at shed light upon a basic dimension which is to achieve sustainability of the cultural and social identity of the modern Kurdish houses in Erbil city that reflects the effect of the traditional civilization of the Kurdish society. It also reflects the style of distributing the design bases and elements and also using spaces, furniture type and textures. The research theoretical background deals with the cultural and social identity, sustainability, interior design elements and ways of achieving sustainable design. The research has achieved a number of results and the most important one is that the Kurdish society has adapted three directions in designing Kurdish houses. Some houses adapted modernism as their residents were affected by the foreign designs, other houses adapted the heritage-based designs that reveal authenticity and magnificence throughout using textures and colors that are related to the surrounding nature, some other houses are individual and subjective in the kind of the adapted designs chosen by people who are affected by both the modernist and the heritage-based directions. The research also presented some conclusions that reflect the ideas mentioned in the theoretical background. The most important conclusion is that the cultural and social identity is noticeably present in the most of the interior designs and distributing their elements and depending on the Kurdish heritage and also coping with the modern designs so the Kurdish house is deep-rooted to its heritage and this is what makes it unique and special.
\end{abstract}




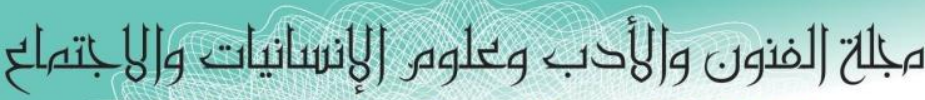
Journal of Arts, Literature, Humanities and Social Sciences

ISSN online: 2414 - 3383

ISSN print: 2616 - 3810

\section{العدد (45) \\ Volume (45) November 2019}

\section{الفصل الاول \\ مشكلة البحث واهميته}

اولا: مشكلة البحث وا هميته

تقوم مشكلة البحث الحالي على ضرورة التهرف التعرف على المحددات التقافية و الاجتماعية في التصميم الداخلي

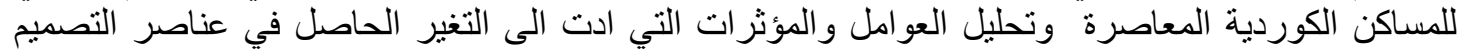

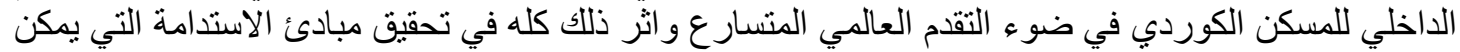

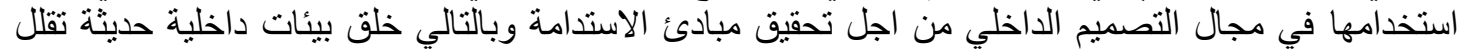
وتخفض الضرر على البيئة و على الافر اد من اجل حفظ الموارد النّ و الطاقات للاجيال القادمة. ثانيا: الثداف البحث

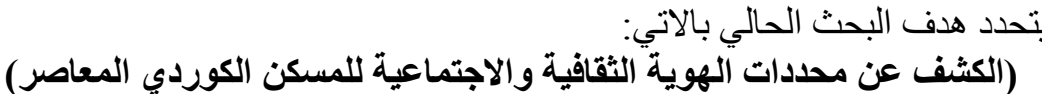

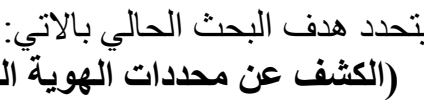

ثالثا: حدود البحث

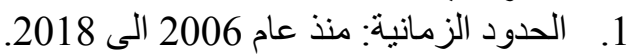

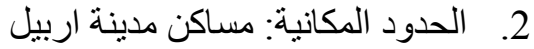
3. الحدود الموضو عية: الهوية الثقافية و الاجتماعية، التصميم الداخلي المستدام. رابعا: مصطلحات البحث البث

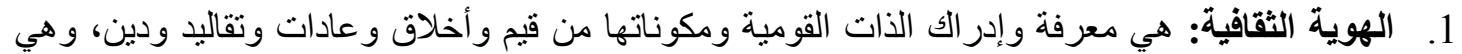

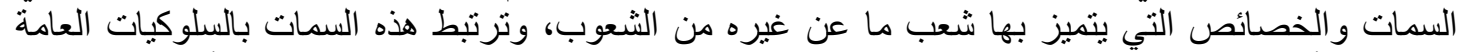

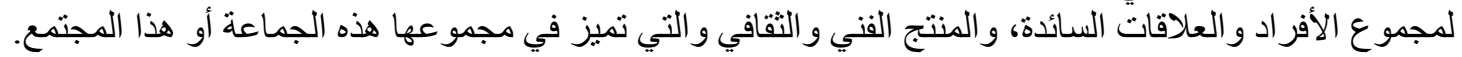

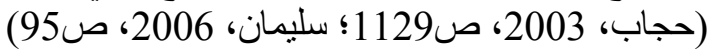

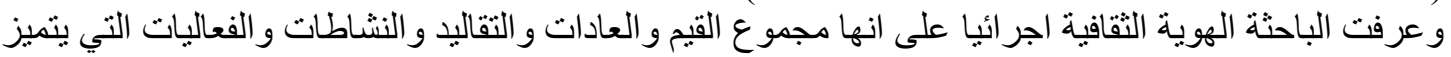

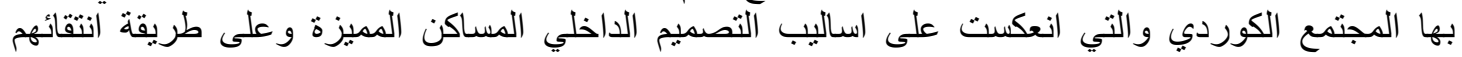

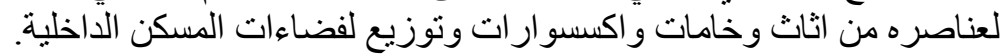

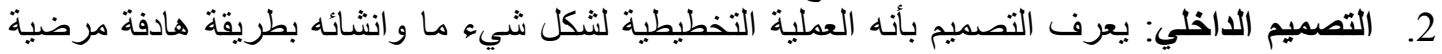

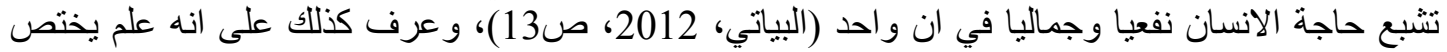

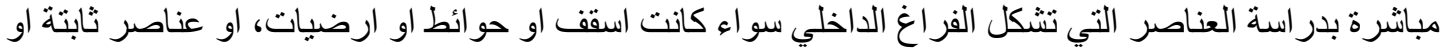

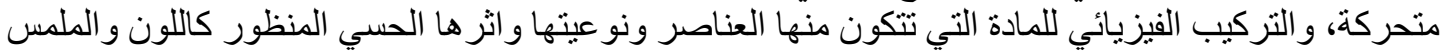

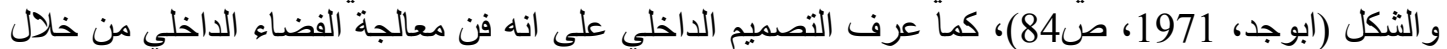

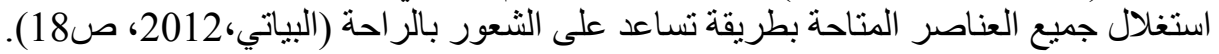

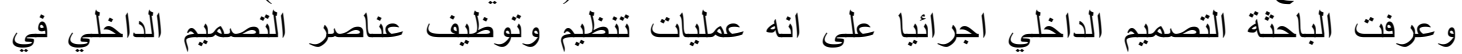

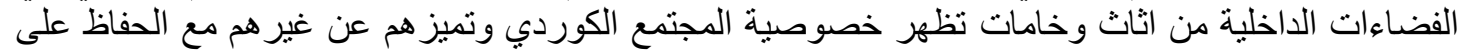

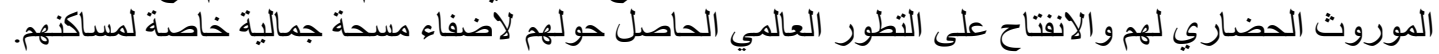

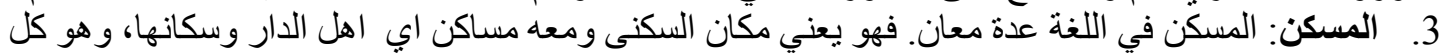

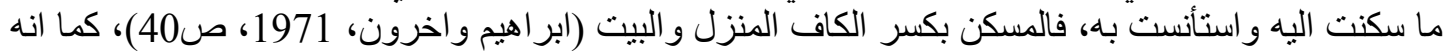

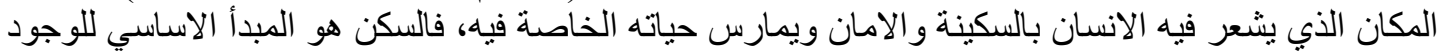

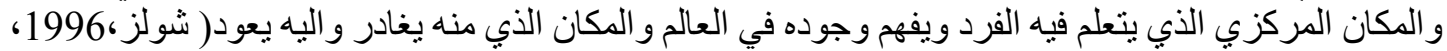

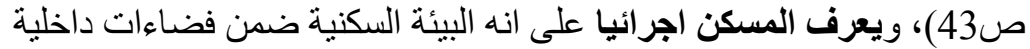

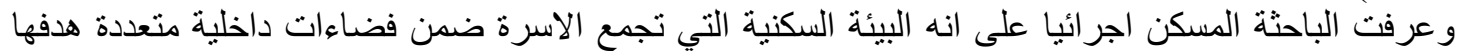

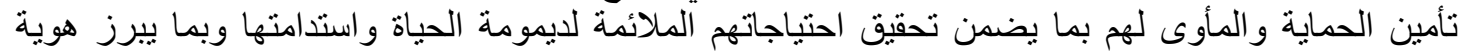

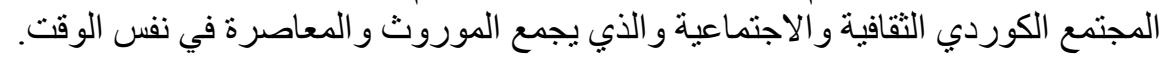


مجلحت (لفنون والأدب وتلوه الإنسانيات والبغتهماع Journal of Arts, Literature, Humanities and Social Sciences

ISSN online: 2414 - 3383

ISSN print: 2616 - 3810

2019 نوفمبر Volume (45)
العدد (45) November 2019

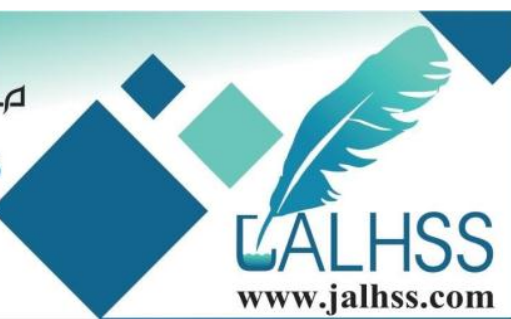

الاطار النظري الثاني

\section{اولا: التصميم الداخلي \\ 1. الا: مفهوم التصميم الداخلي الدي}

يعد التصميم الداخلي مجالا حديثا نسبيا فهو علم ومهنة تؤدي دورا حيويا في تأقلم الإنسان مع بيئته عبر توفير فر اغ داخلي يلبي حاجات المستخدم المختلفة. و هو يختص بتحديد العلاقة بين شاغلي المبنى وفر اغات البيئة البئة

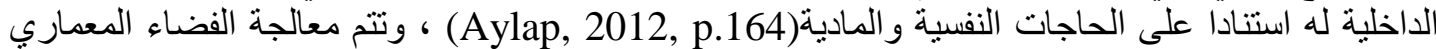
بأبعاده المختلفة جميعها بطريقة يجري من خلالها استغلال عناصر التصميم جميعها مع الاهتمام بالجانبين

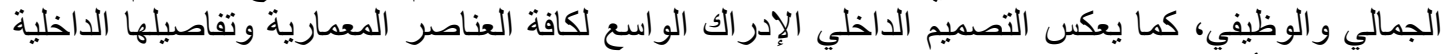

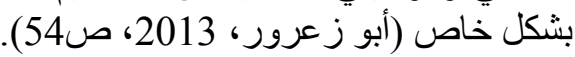
يتضمن التصميم الداخلي عمليتي التخطيط والابتكار استنادا إلى معطيات معمارية محددة تسهم في اخراج

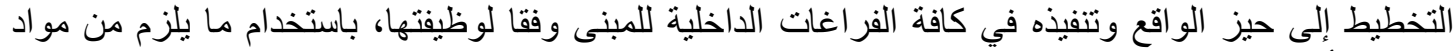

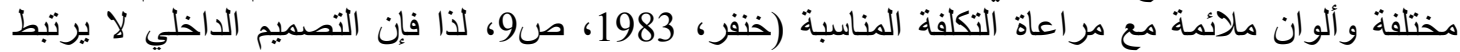

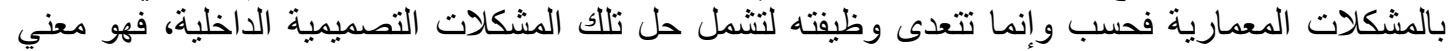
بمعالجة كثير من المشكلات وايجاد الحلول لاي معيقات من اجل سهولة استخدام العناصر التصديمة المبلة المختلفة من

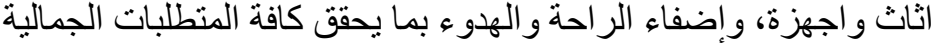

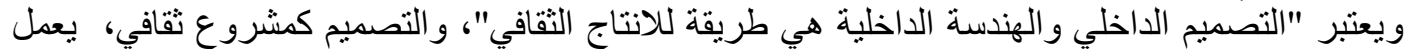
على صنع اجواء للمكان الذي يفسر ويترجم ويحرر رأس المال الثقافي في عالم عالمي، وهو يلعب دورئ دورا في

تسهيل الابقاء على التنوع الثقافي". (IFI, 2013, p.26)

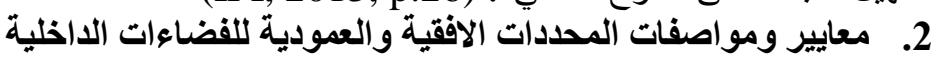

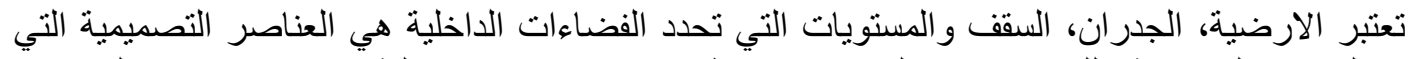
تحدد الحدود الفيزياوية للفضاء وتفصله عما يحيطه من فضاءات داخلية اخرى، وعن الفضاء الخارجي.(Ching, 1987, p.11)

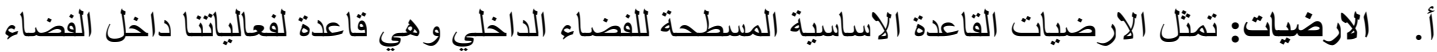
فضلا عن كونها قاعدة للاثاث، وقد تكون الارضية الجزء الاساسي في التركيب الانشائي او ملحق بالارضية الأية

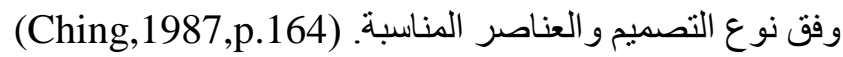

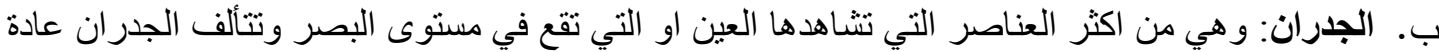

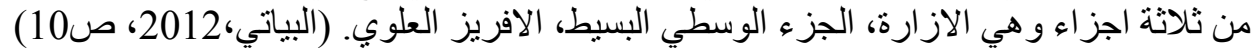

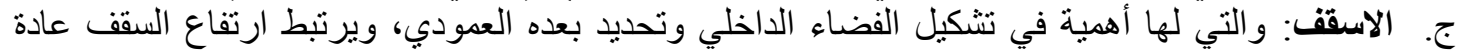

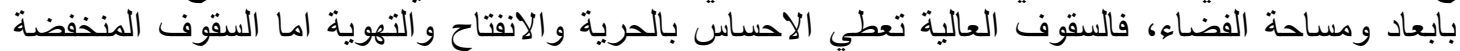

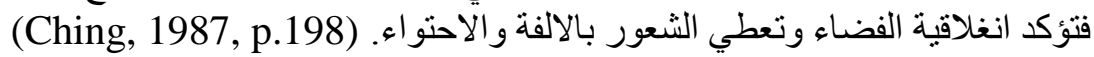
كما ويمكن تقسيم عناصر التصميم الداخلي الى قدئ التمين:

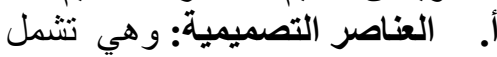

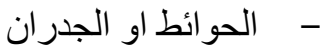
- - - الاسقف النوالـ - - - الارضيات -

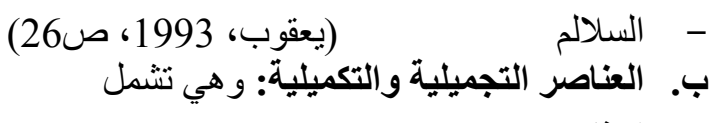
- 


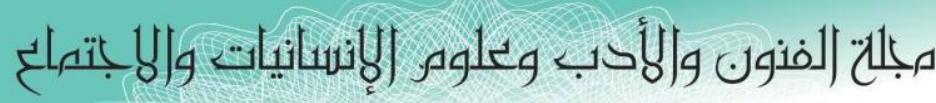
Journal of Arts, Literature, Humanities and Social Sciences

ISSN online: 2414 - 3383

ISSN print: 2616 - 3810

2019 نوفر نوبر Volume (45)
العدد (45) November 2019

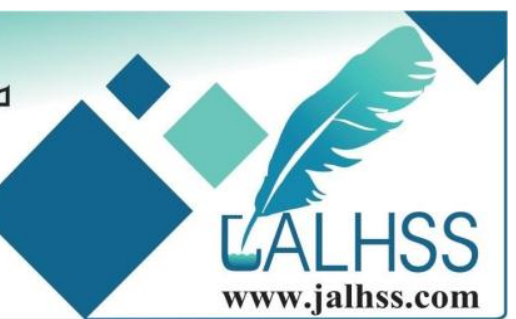

www.jalhss.com

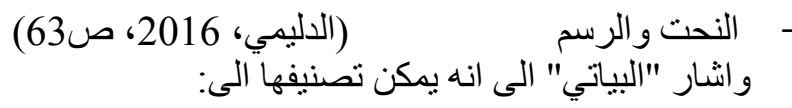

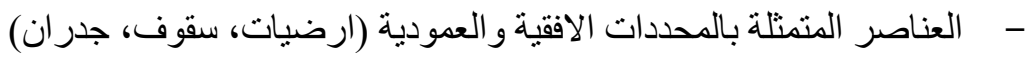

- - المفاصل الانتقالية بين الفضاءات (ابو اب، شبابيك، سلالم )

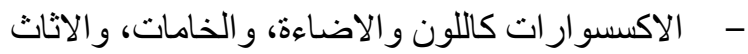

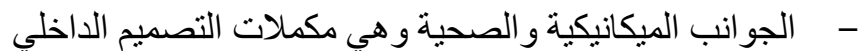

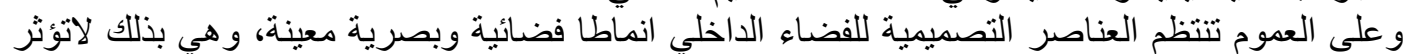

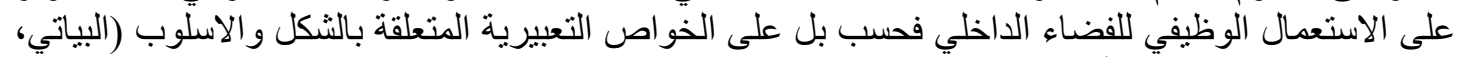

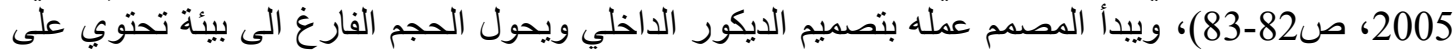

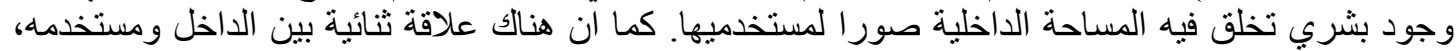

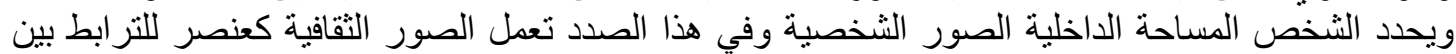

عناصر التصميم. (Ayalp, 2012, p.162) 3. الفضاءات الداخلية للمسكن

يتألف المسكن من مكونات تختلف في عددها ومساحتها من مجتمع لاخر ومن اسرة لأخرى، وفقا

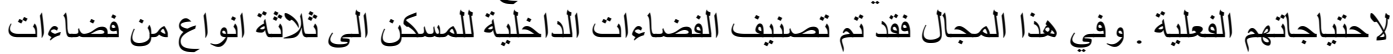

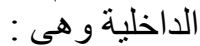
أ. فضاءات عامة: حيث نوفر هذه الفضاءات الداخلية العامة اجر اء فعاليات مشتركة عامة وتتمثل في المساكن بغرف الجلوس و المعيشة.

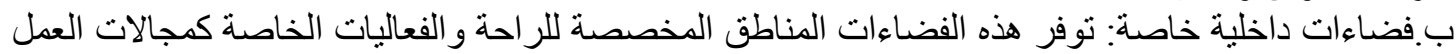

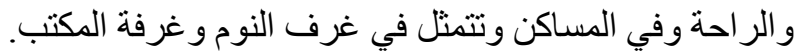

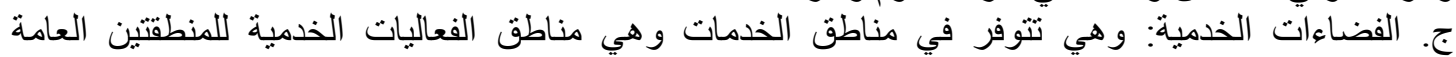

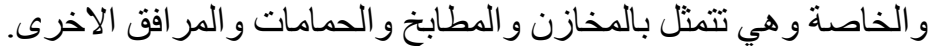

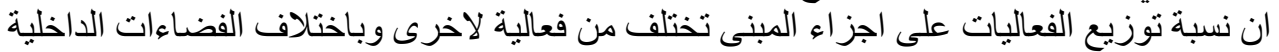

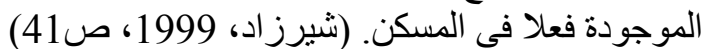

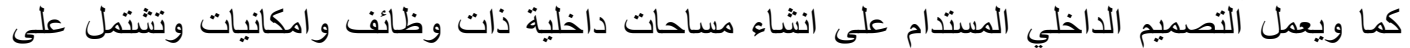

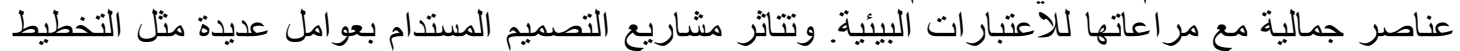

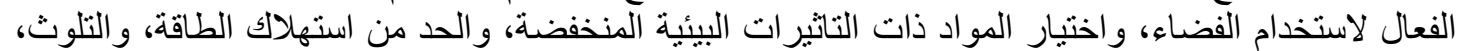

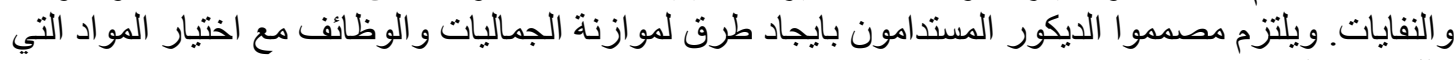

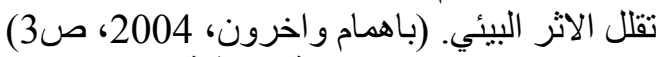

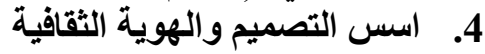
اشتار "الفران" الى مجمو عة من محددات الهوية الثقافية وهي تعتمد على مجمو عة من الاسس وهي: (الفران، (609-603، 2019 أ. مركز السيادة: ويكون التاكيد عليها من خلال وجود نقطة محورية في كل فضاء داخلي تلفت النظر اليها من النا

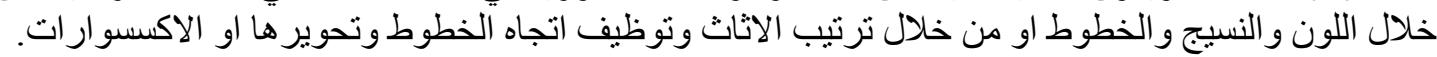

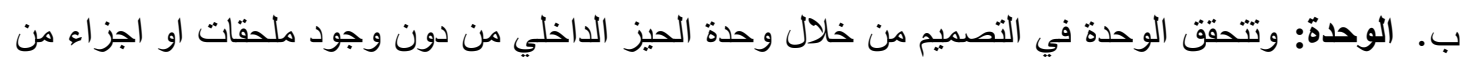

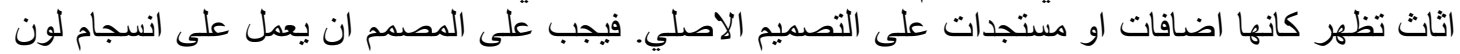

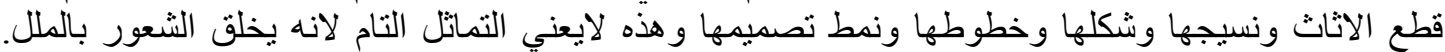

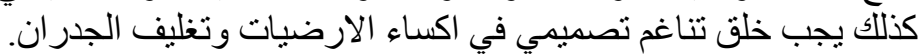




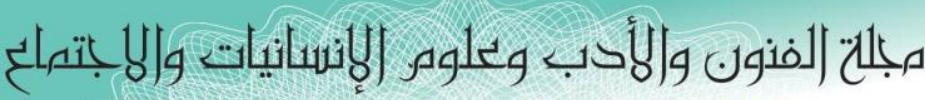
Journal of Arts, Literature, Humanities and Social Sciences

ISSN online: 2414 - 3383

ISSN print: 2616 - 3810

\section{9 نوفر Volume (45)}

العدد (45) November 2019

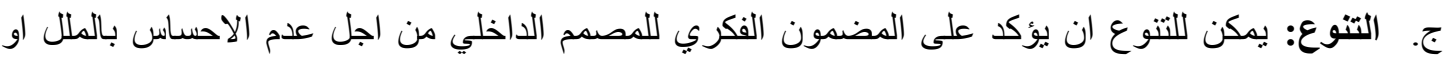

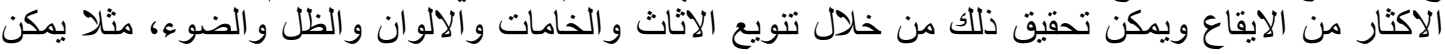

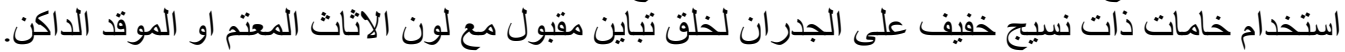

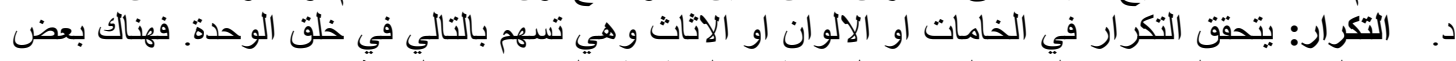

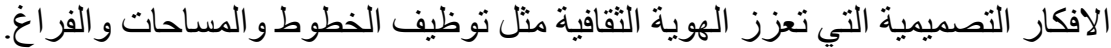

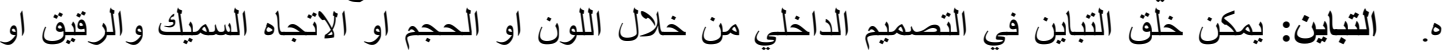

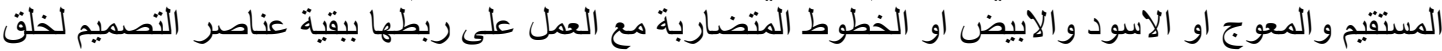

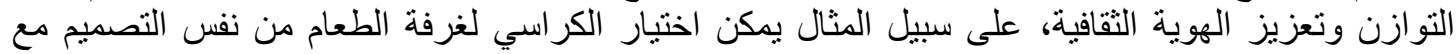

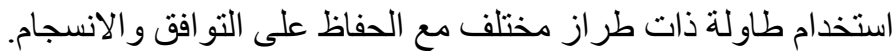

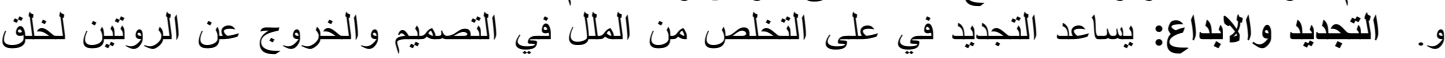

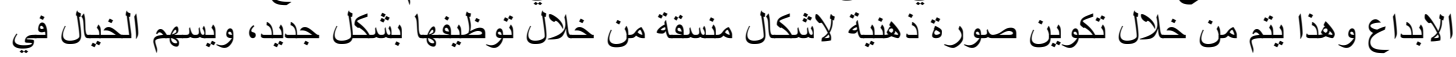

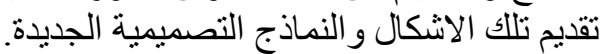

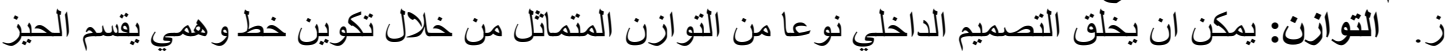

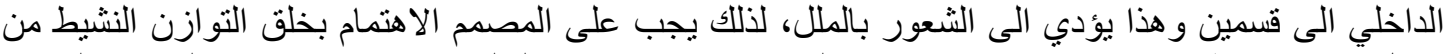

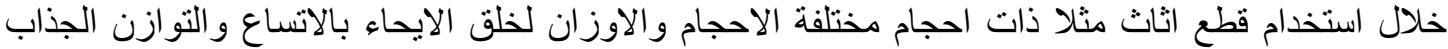

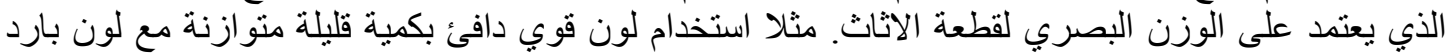

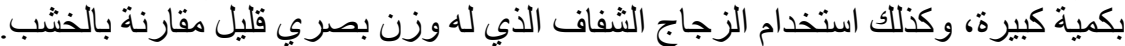

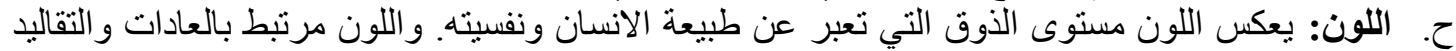

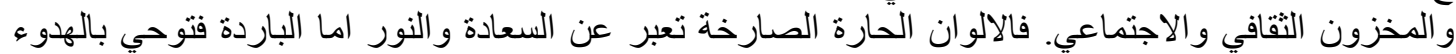

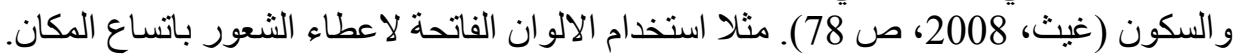

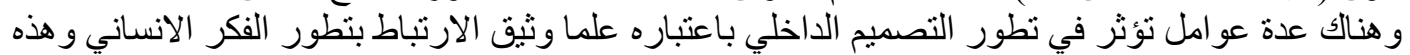

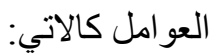

أ. العو امل التفكرية والثقافية والدينية بالاضافة الى تاثير التيار ات الفكرية المختلفة.

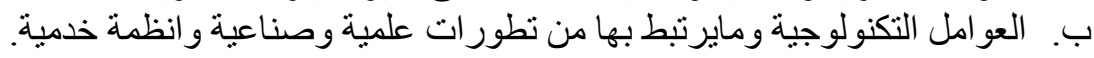

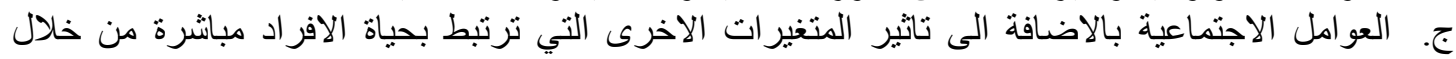
انشطتهم الحياتية المختلفة.

د. رو اد العمارة و التصميم الداخلي وما يبتكرونه او بطورونه من تصميمات للفضاء التهات الداخلية و عناصر ها. ه. المنتجات الصناعية المحلية والعالمية التي تصل الى الى المستهلك او المصمم عن طريق المعارض.

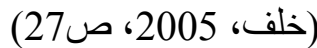

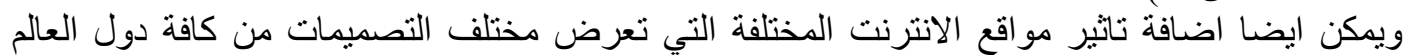

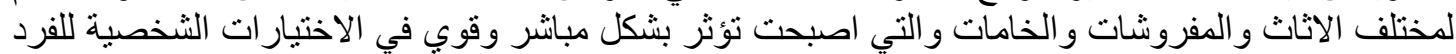

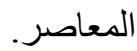

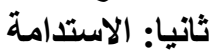

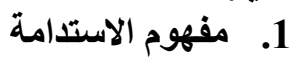
تعرف الاستدامة على انها "تلبية احتياجات الاجيال الحالية دون الاضرار بقدرة الاجيال القادمة على تلبية احتياجاتها" (Sustainable Community Profile , 1995)

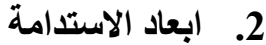

يمكن تحديد ابعاد الاستدامة بالاتي:

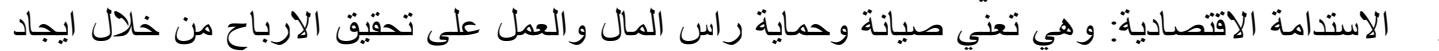

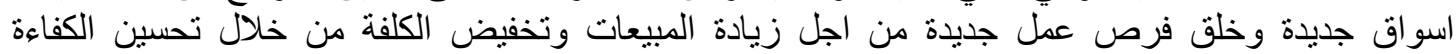

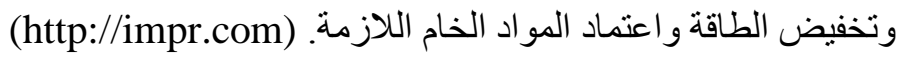

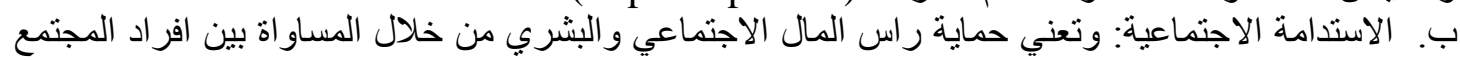

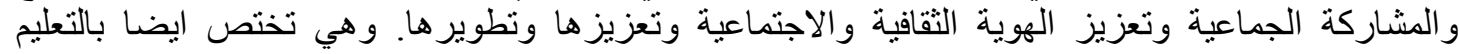




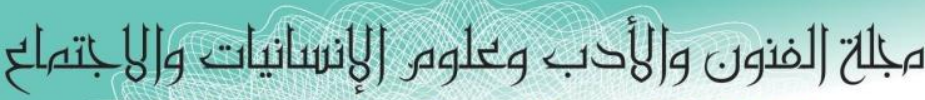
Journal of Arts, Literature, Humanities and Social Sciences

ISSN online: 2414 - 3383

ISSN print: 2616 - 3810

\section{9 نوفمبر Volume (45)}

(45) (4) (4) November 2019

وتطويره بحيث يكون حق لكافة افراد المجتمع وهي ايضا تهتم بالتطور الصحي والتغذية ومعالجة البطالة

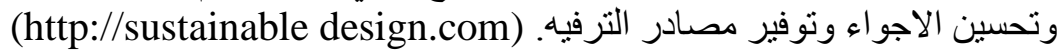

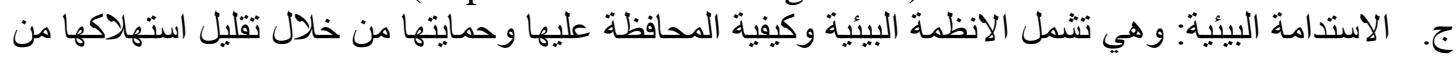

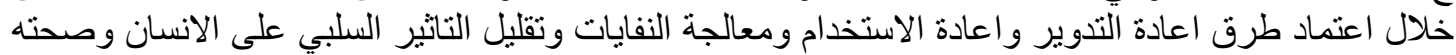

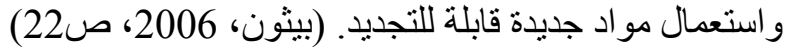

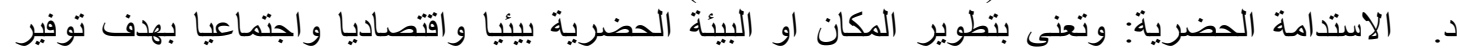

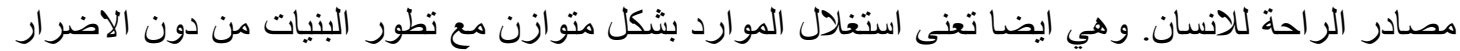

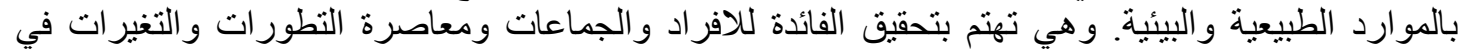
احتياجاتهم مع الحفاظ على حقوق الاجيال القادمة. (Goodland, 1996, p.2)

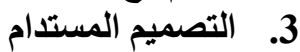

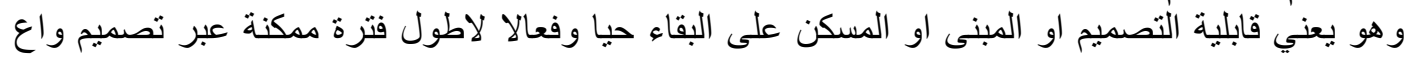

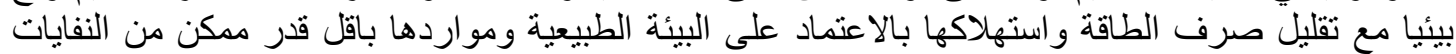

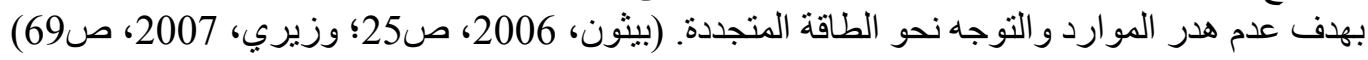

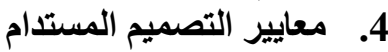
ظهرت معايير عالمية تخنص بقياس الاستدامة في التصميم او المبنى من اجل تحديد كفاءة المبنى وهي كالاتي:

- BRREAM = Building Research Establishment Environment Assessment Method. في بريطانيا 1990

- LEED = Leadership in Energy and Environment Design. في الو لايات المتحدة الامريكية .2000

ويعتبر معيار LEED الاكثر شهرة. وبحسب معاييره فان كفاءة استهلاك المبنى له (17 نقطة) وكفاءة

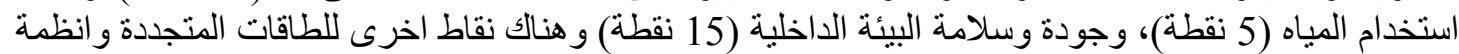

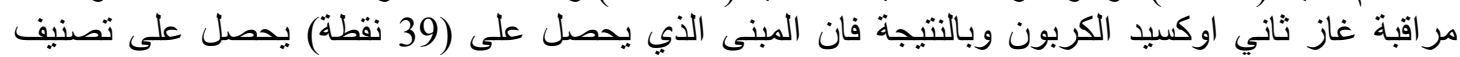

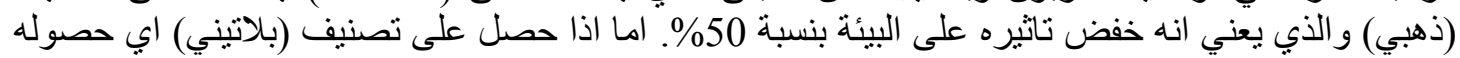

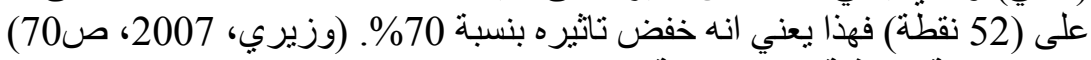

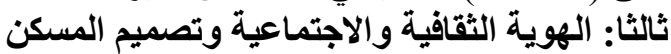

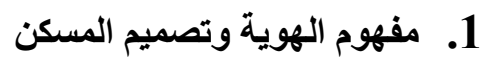

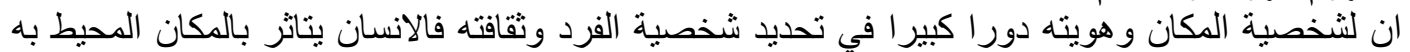

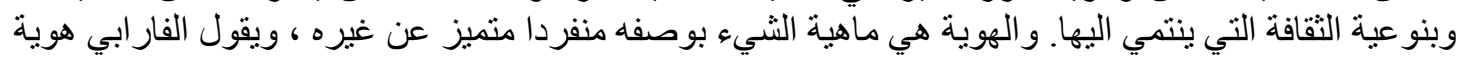

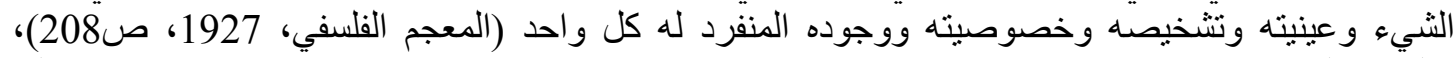

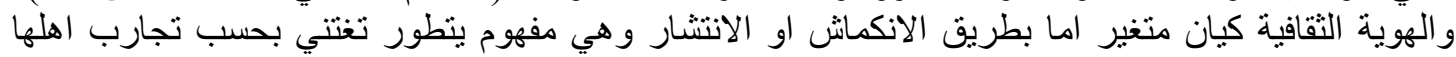

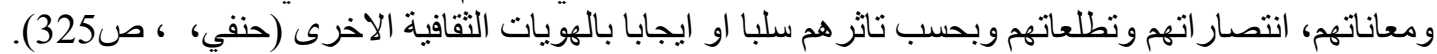

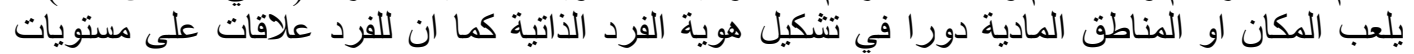

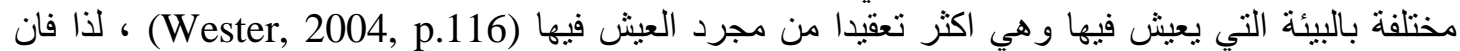

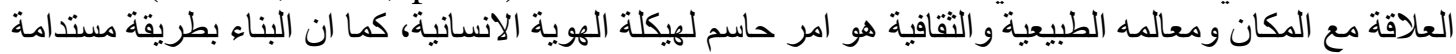

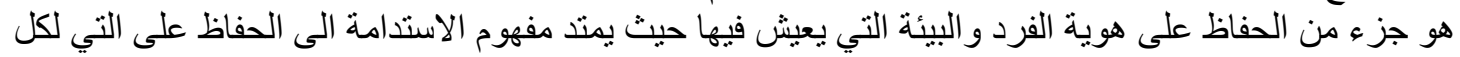

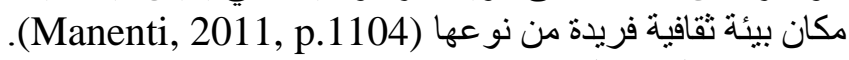

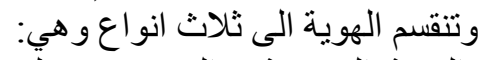

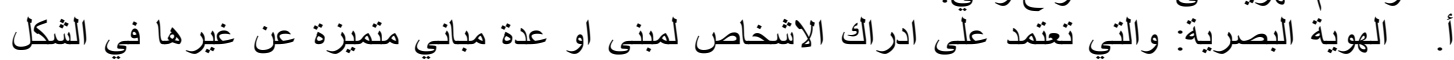

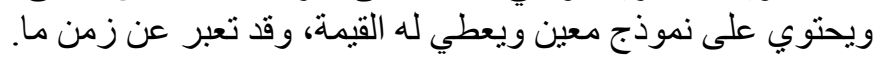

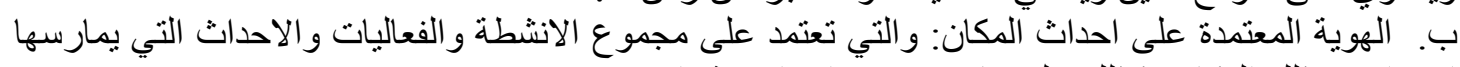

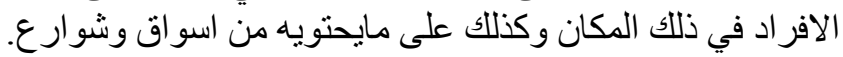




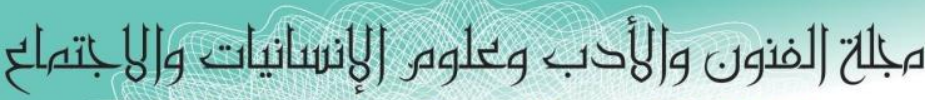
Journal of Arts, Literature, Humanities and Social Sciences

ISSN online: 2414 - 3383

ISSN print: 2616 - 3810

\section{9 نوفر Volume (45)}

العدد (45) November 2019

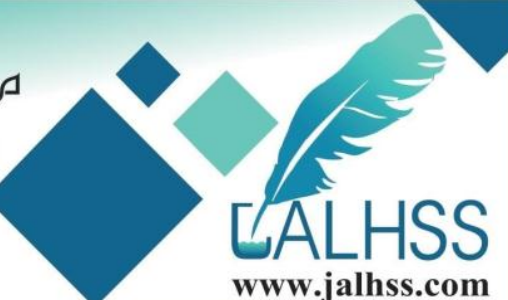

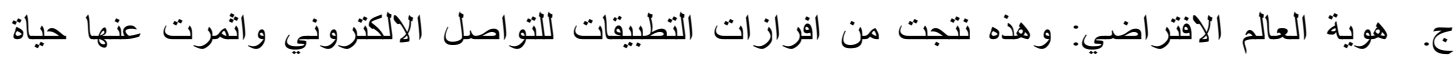

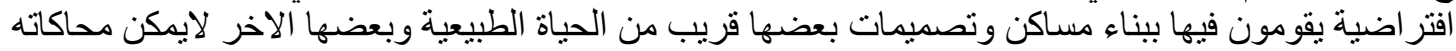
و اقعيا. (نفس المصدر السابق) ويمكن نوظيف انواع الهوية المذكورة في اعلاه في التصميمات الداخلية للمساكن حيث ان لكل الكن مسكن هوية

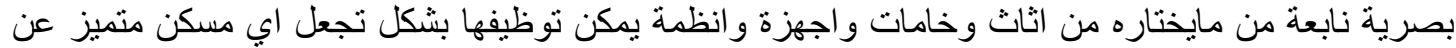

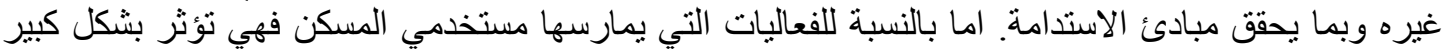

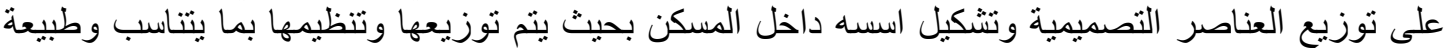

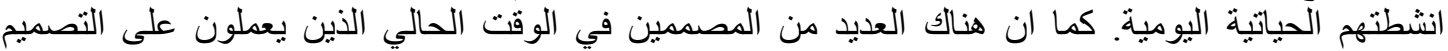

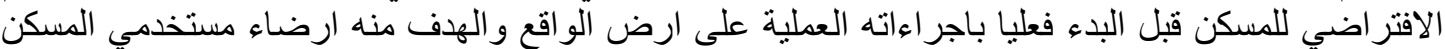

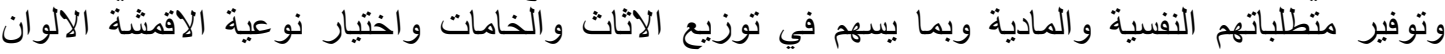

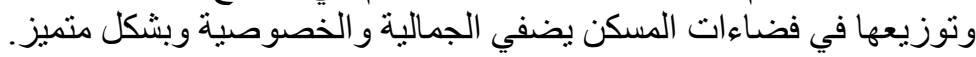

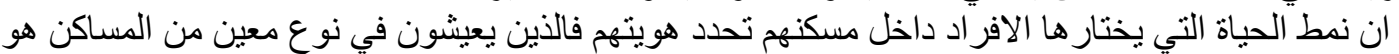
بالحقيقة تعبير عن نمط حياتهم داخل ذللك المسكن واسلوب حياتهم هذا هو هويته هويتهم (Clapham, 2005)، فطريقة توزيعهم للاثاث مثنلا تحدد نمط سلوكهم في في مسكنه

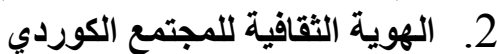

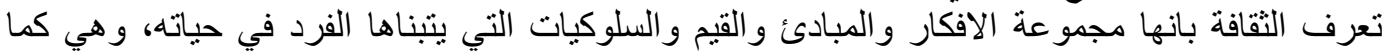

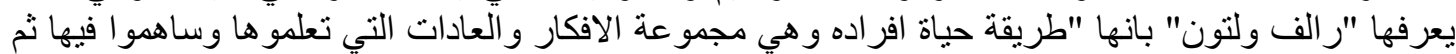

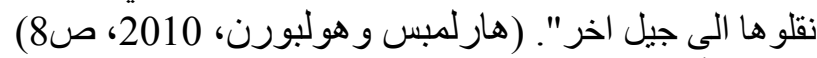

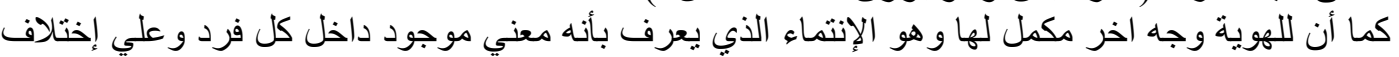

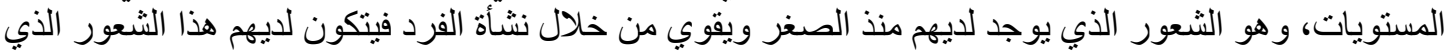

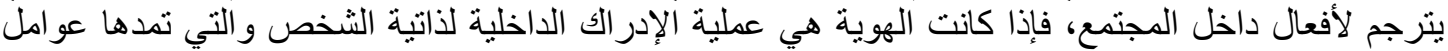

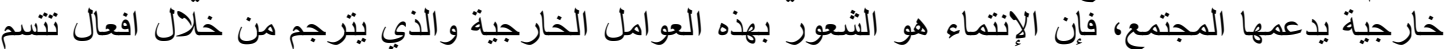

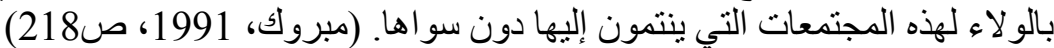

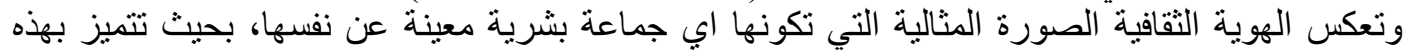

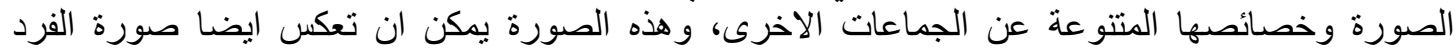

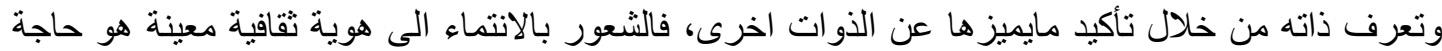

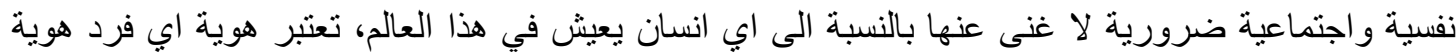

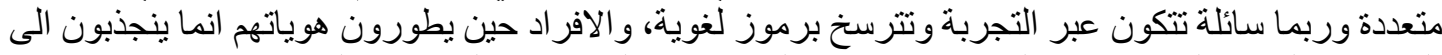

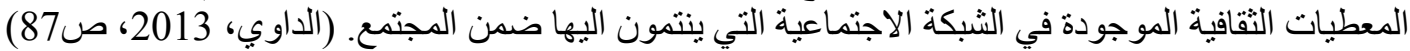

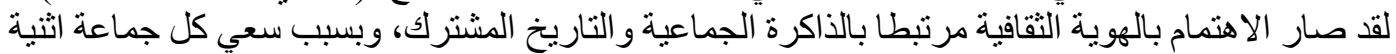
لاثبات هويتها الثقافية والانتماء اليها، ظهرت محاو لات كثيرة تنتبنى مفهوم "هيمنة الثقافات". (نفس المصدر

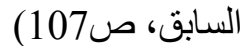

لقد تطور مفهوم الثقافة نتيجة للتطور الكبير في كل مدن العالم، وبما ان الثقافة ترتبط بمكونات المجتمع، فانها

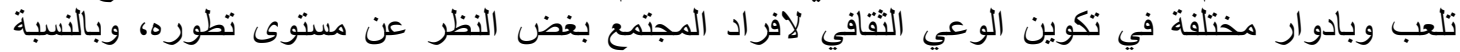

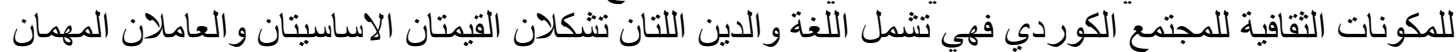

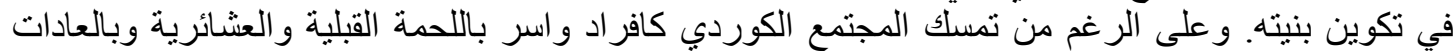

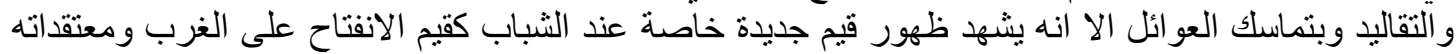

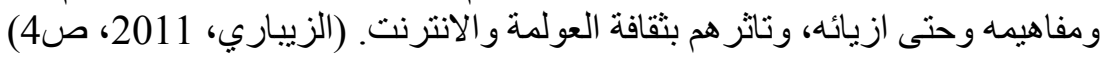

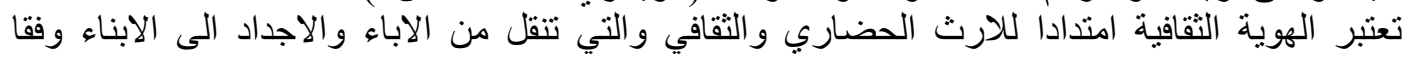

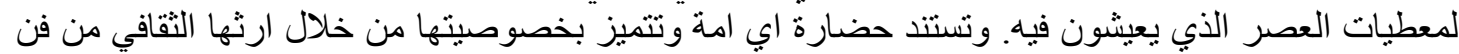

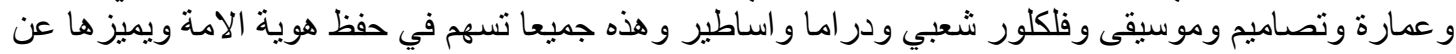

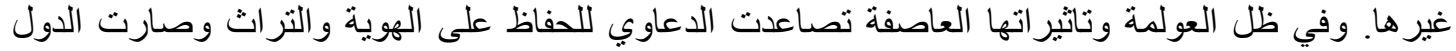




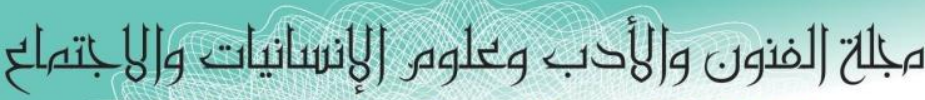

Journal of Arts, Literature, Humanities and Social Sciences

ISSN online: 2414 - 3383

ISSN print: 2616 - 3810

\section{9 نوفر \\ Volume (45)}

العدد (45)

November 2019

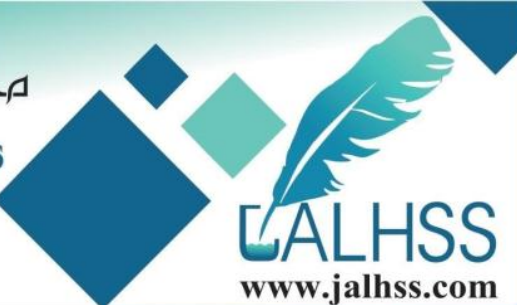

و الامم تهتم بسيادة ثقافتها حتى لاتضمحل او تذوب حضار اتها بسبب سيادة ثقافات الامم الاقوى اقتصاديا. فالثقافة

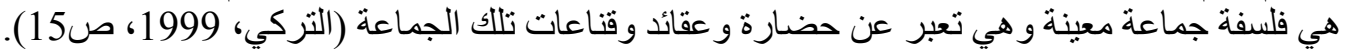

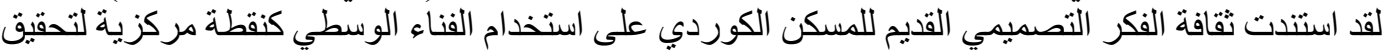

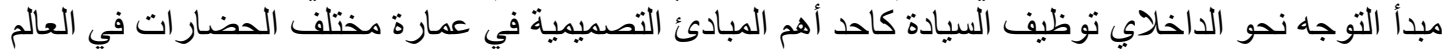

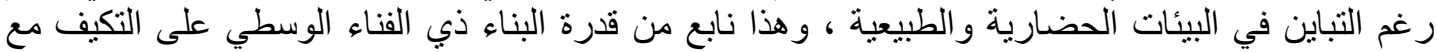

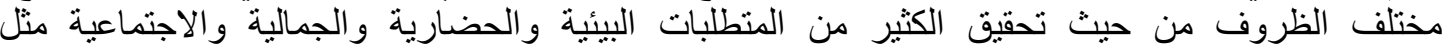

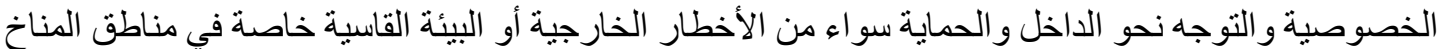

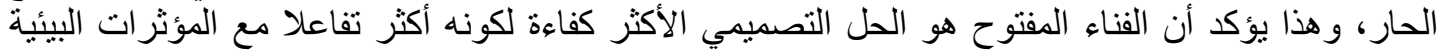

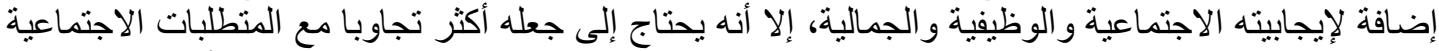

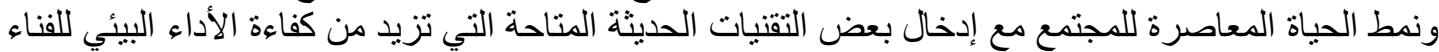

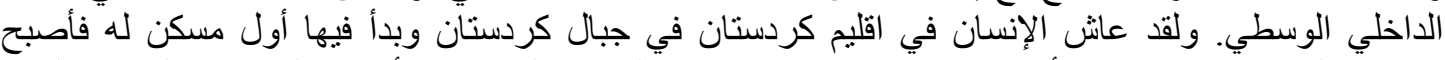

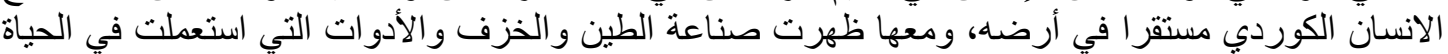

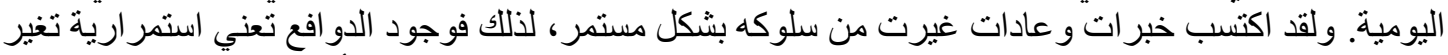

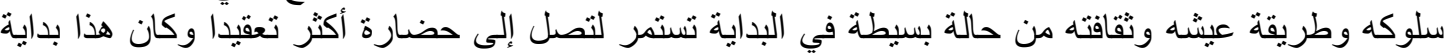

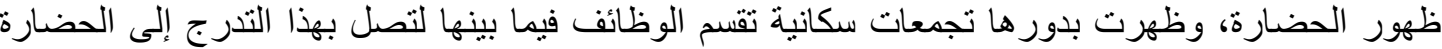

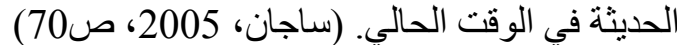

ويمكن تحديد تطور الثخصية الأساسية للشعب الكوردي بالاعنماد على ثقافته ونمط المز ايا السايكولوجية

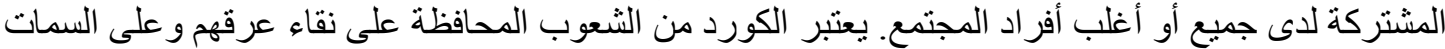

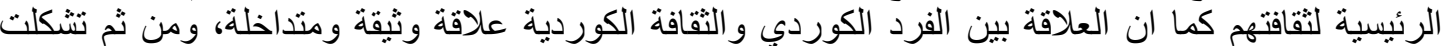

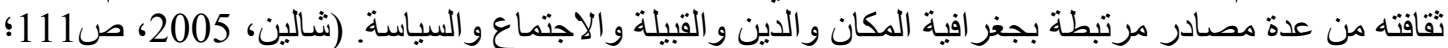

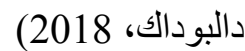

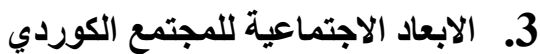

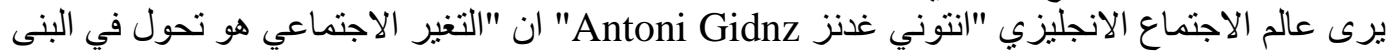

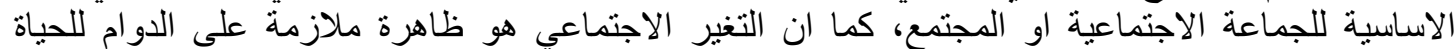

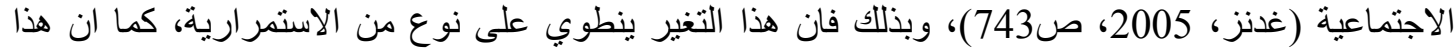

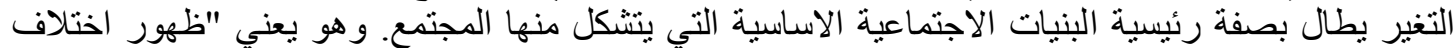

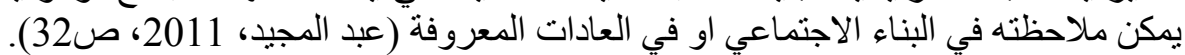

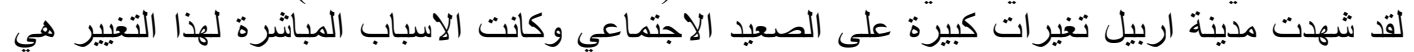

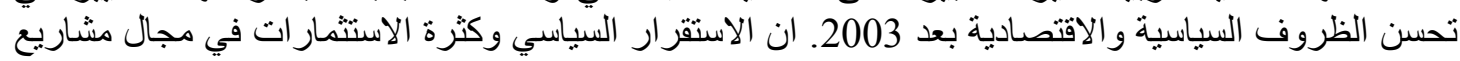

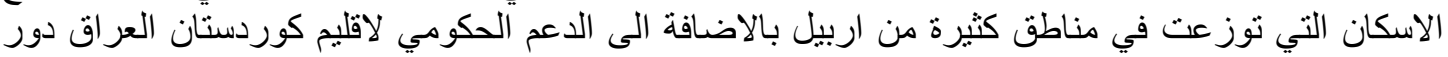

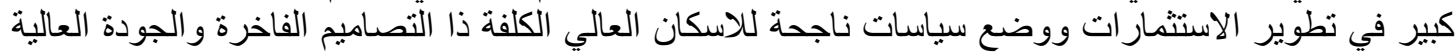

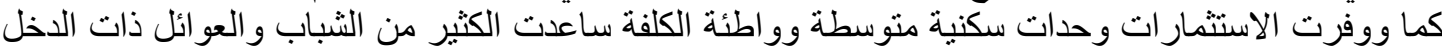
المحدود في الاستقر ار وبالتالي تحسين ظروفهم الاقتصادية و الاجتماعية. 


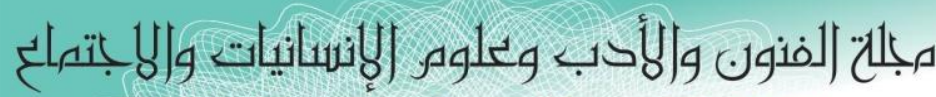
Journal of Arts, Literature, Humanities and Social Sciences

ISSN online: 2414 - 3383

ISSN print: 2616 - 3810

\section{9 نوفمبر} Volume (45)
(45) (40) November 2019
¿ÁLHSS www.jalhss.com
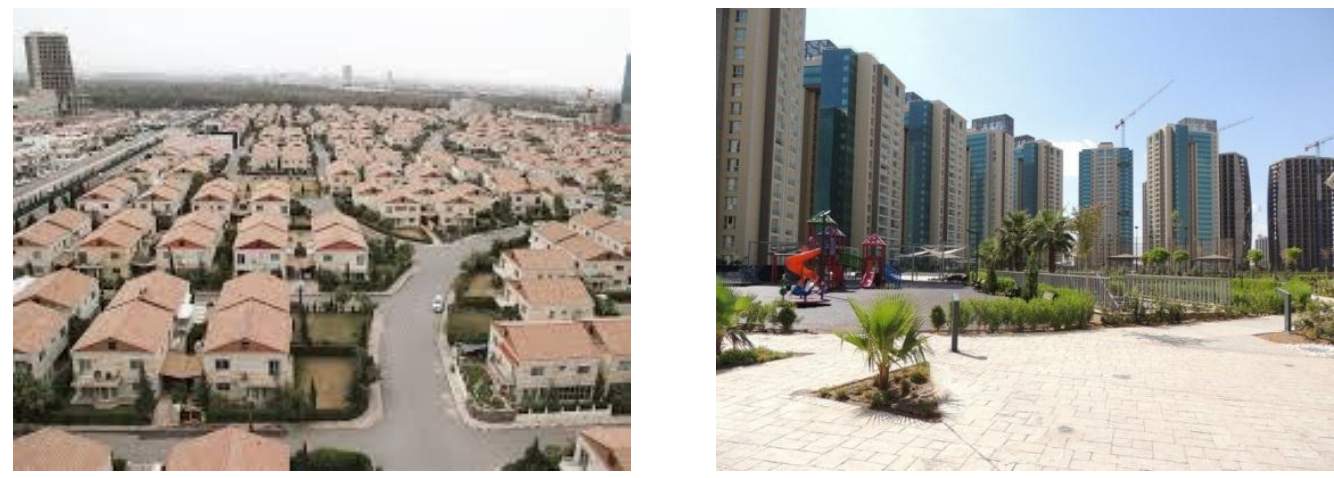

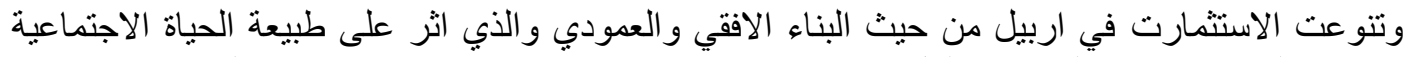

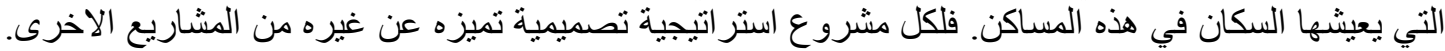

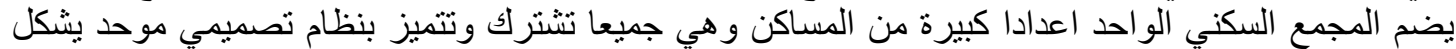

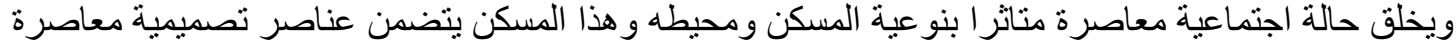

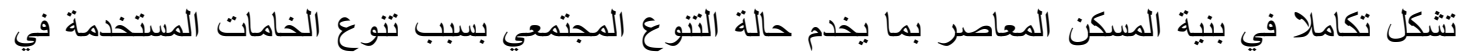

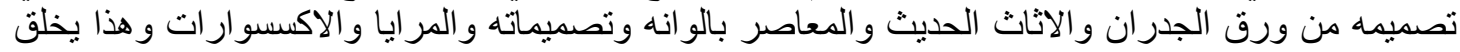
طاقة ايجابية في المكان تتعكس جماليا على وحدة التصميم الداخلي لهذا المسكن و الفر ادها

\section{الفصل الثالث منهجية البحث التصث}

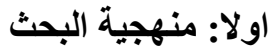

اعتمدت الباحثة المنهج الوصفي المسحي للحصول على البيانات والمعلومات والعمل على تحليلها لتحقيق

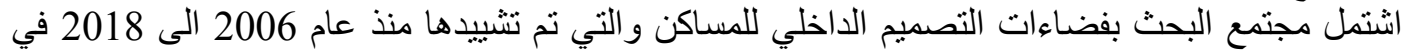

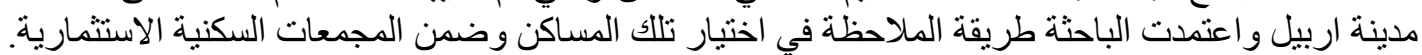

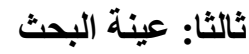

تم اختيار عينة البحث بطريقة قصدية من بين مجتمع البحث وتكونت العينة من (30) مسكن لدر اسة وتحليل التصميمات الداخلية لتللك المساكن ومن مجمعات سكنية مختلفة.

رابعا: اداة البحث الإث

اعتمد الباحث طريقة الملاحظة وعلى وفق المحاور ادناه:

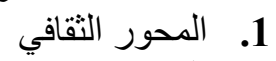

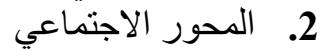

3. 4. محور توظيف الخامات وتنو عها

خامسا: النتائج

توصلت الباحثة الى عدد من النتائج و هي:

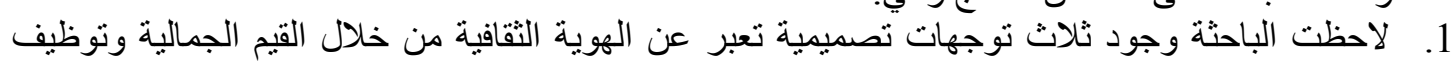
عناصر التصميم الداخلي و هذه التوجهات كالاتي: توجيات 


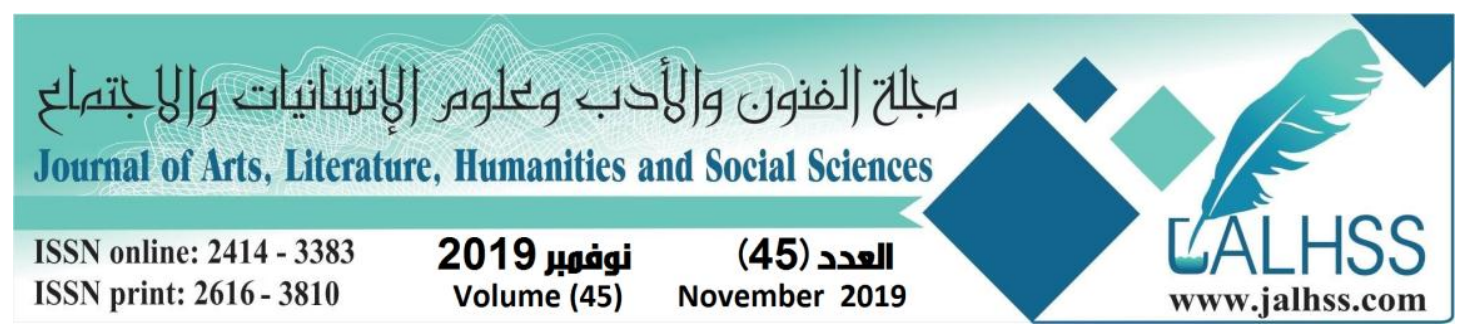

$$
\text { أ. التوجه نحو الاسلوب المعاصر (المتاثر بالتصميم الغربي) }
$$

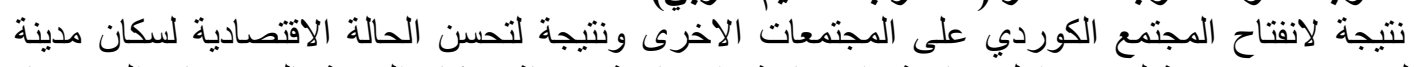

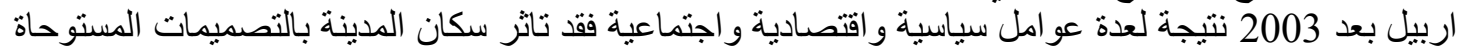

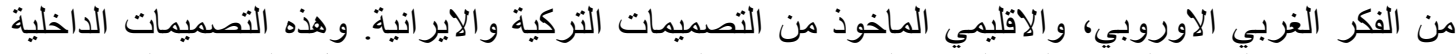

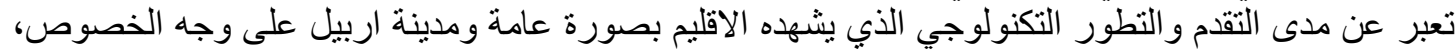

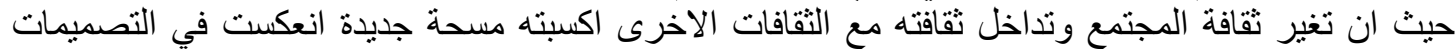

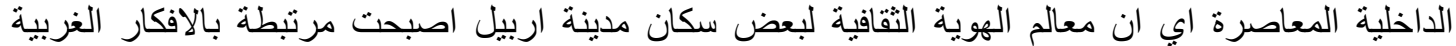

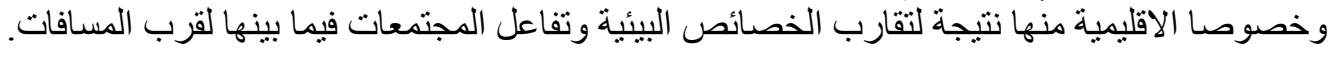
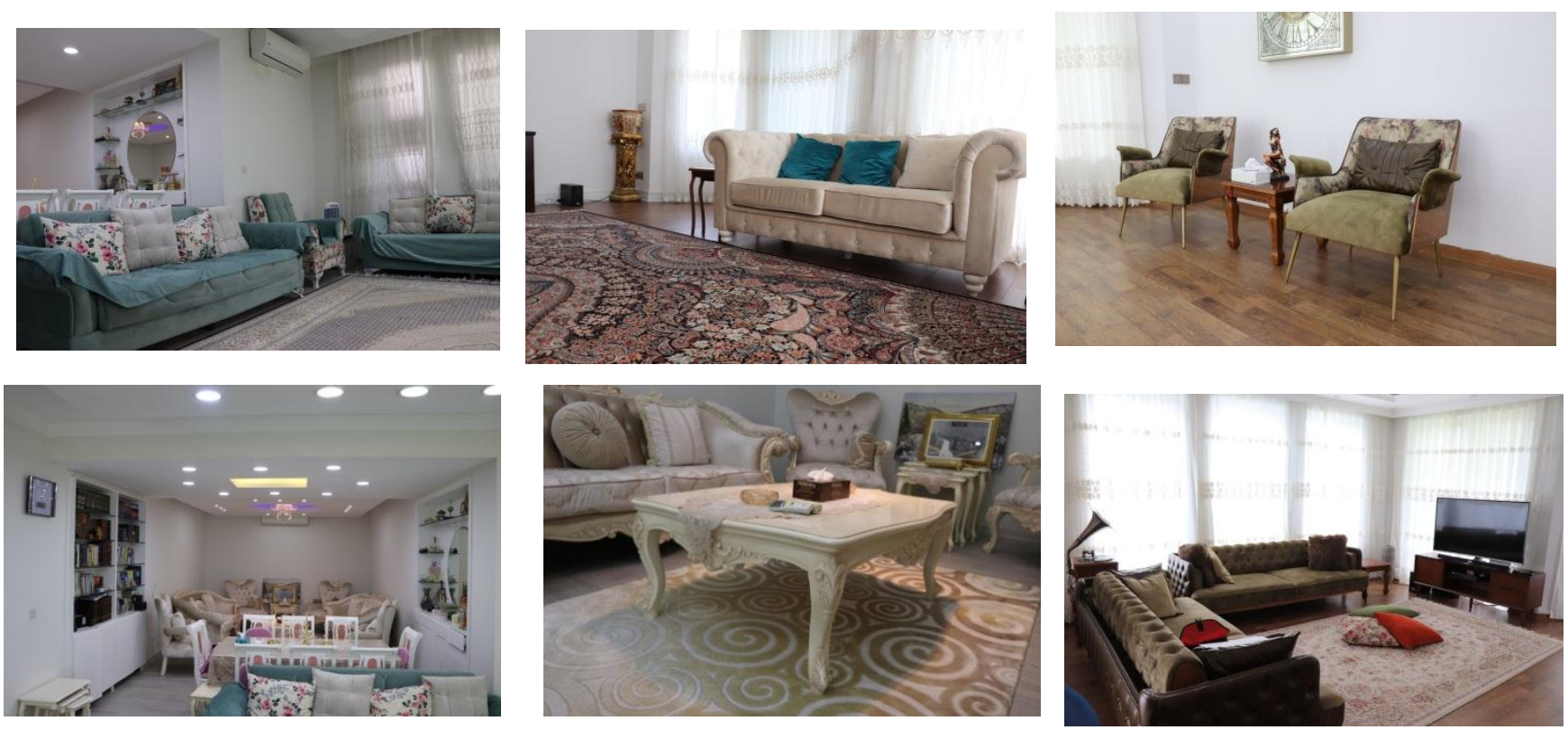

ب. التوجه نحو التصميمات التراثية والتاريخية

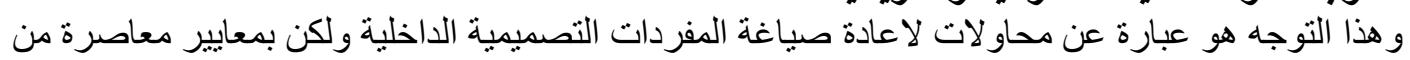

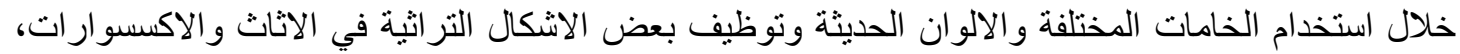

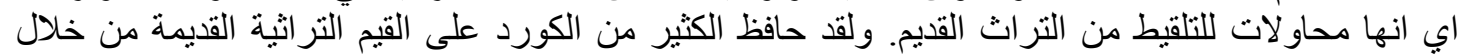

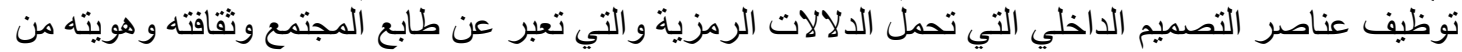

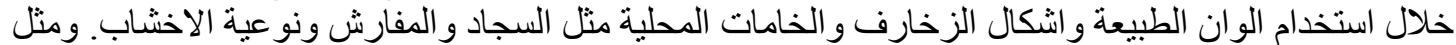

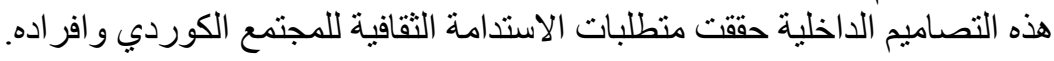



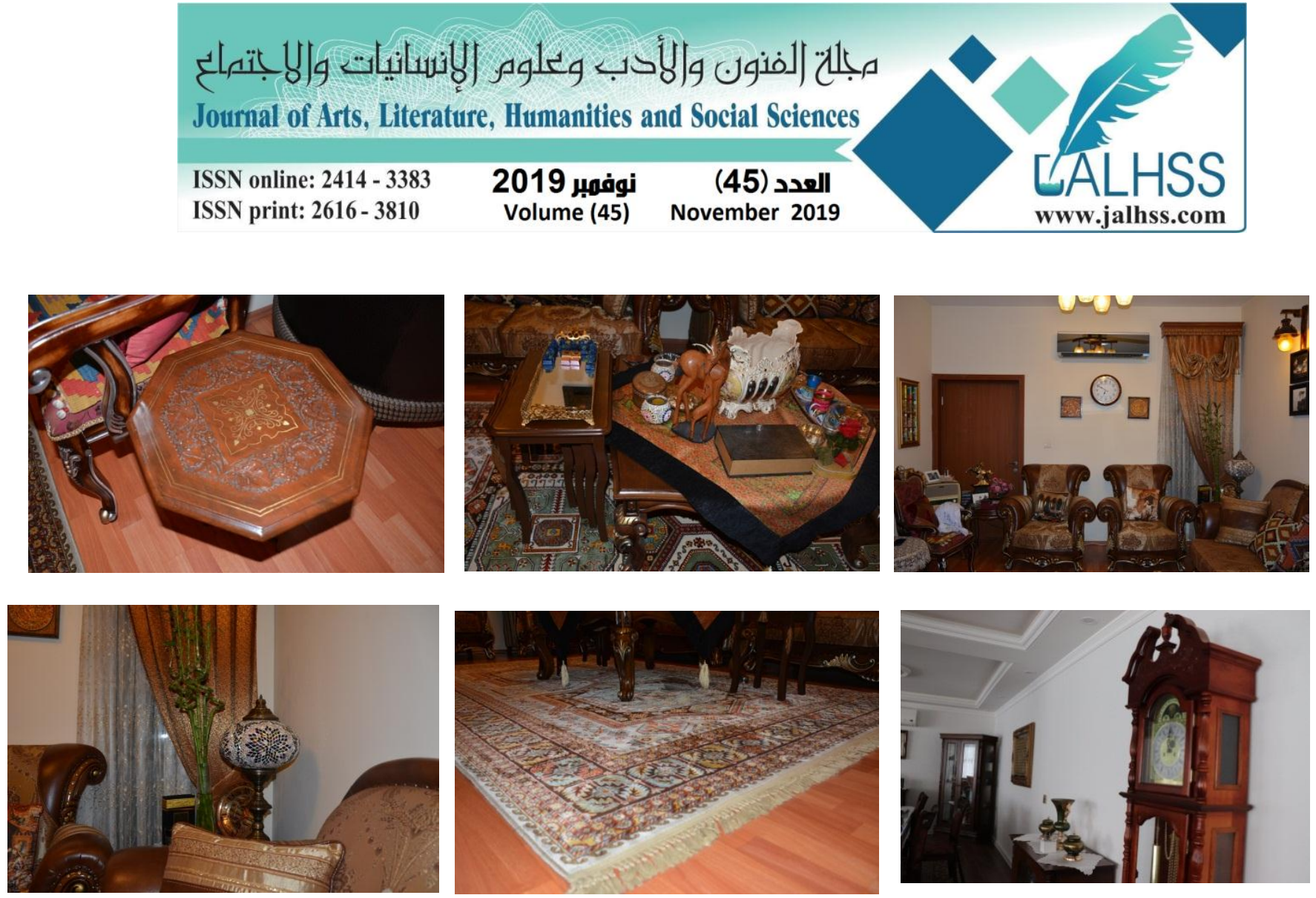

ج. التوجهات الفردية المختلفة: و هذا التوجه يدمج المعاصرة والاصلالة في توظيف التراث المحلي في عناصر

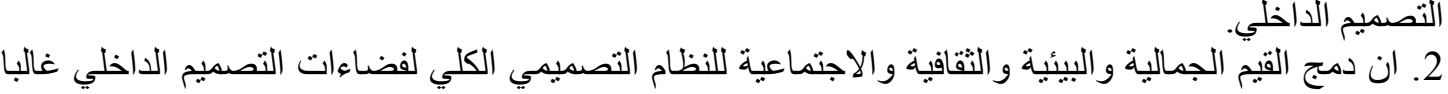

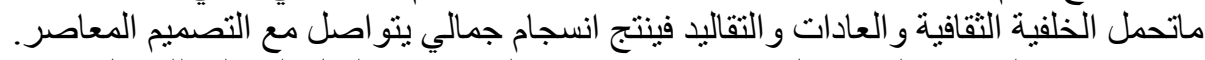
3. ان اختيار الخامات التي تحمل صفات الاستدامة غالبا ماتجسد الفعل الجمالي للتفاعل مع منطلبات البيئة.
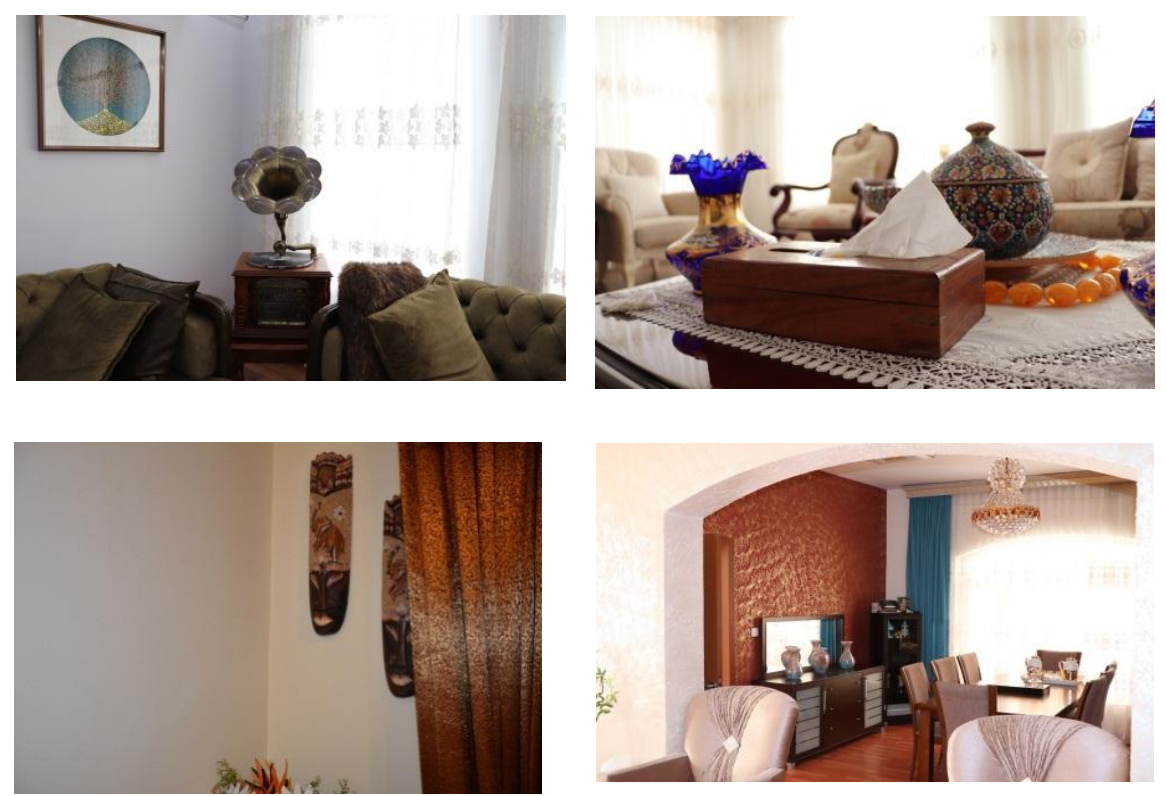
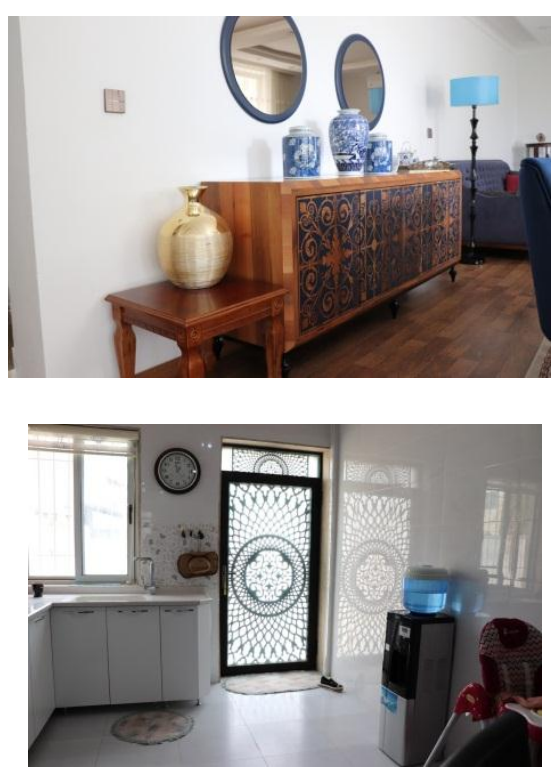


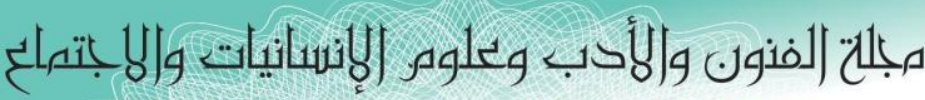
Journal of Arts, Literature, Humanities and Social Sciences

ISSN online: 2414 - 3383

ISSN print: 2616 - 3810

العدد (45)

November 2019

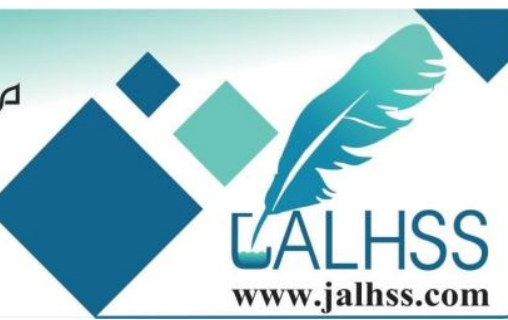

سادسا: الاستتناجات

يعد التوجه نحو نوظيف مفهوم التصميم الداخلي وعلافته بالاثاث والخامات المتنتوعة وتحقيق الموائمة للظروف البيئية المحيطة من خلال تطويع اساليب التصميم لتراعي مبادئ الاستدامة وفق محددات معايير الهوية الإنية الثقافية و الاجتماعية المحلية على وفق الئق الاتي:

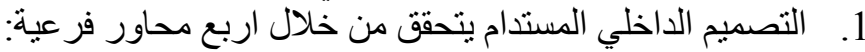

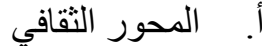

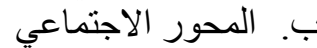
ج. الم المحور التاريخي (الموروث)

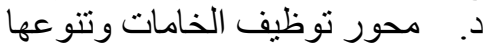

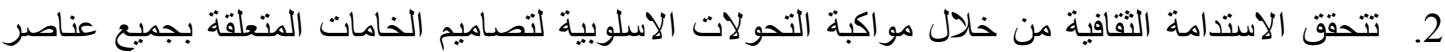

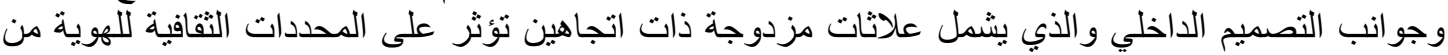

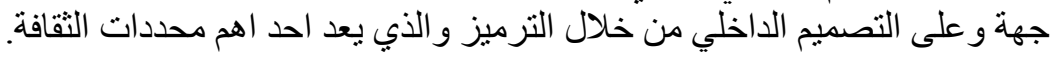

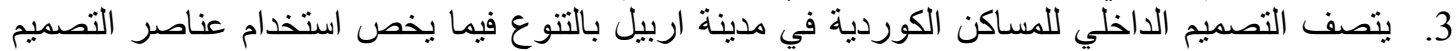

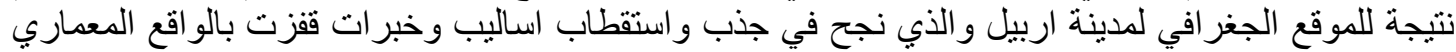
لتجعل من الفرد الكوردي خبير في انتقاء مفردات تلبي حاجاته الاجتماعية و الثقافية و الجمالية.

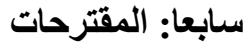
تقترح الباحثة اجر اء دراسة مقارنة للتصميم الداخلي للبيت الكوردي مع البيت التركي.

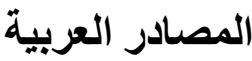

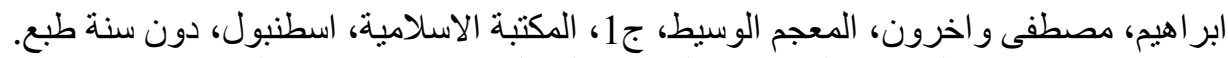

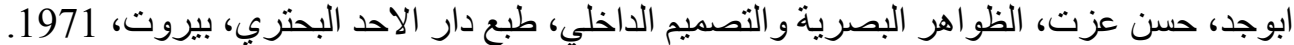

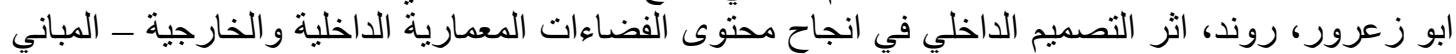

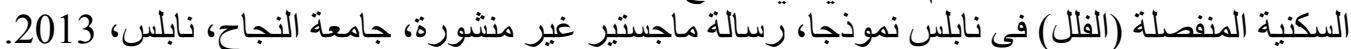

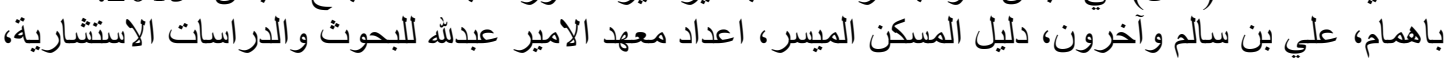

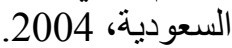
البياتي، نمير قاسم خلف، الف باء التصميم الداخلي، جامعة ديالى، العراق، 2005.

البياتي، نمير قاسم، قو اعد ومفاهيم في التصميم الداخلي، المطبعة المركزية، جامعة ديالى،

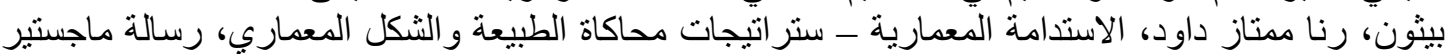

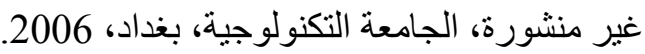

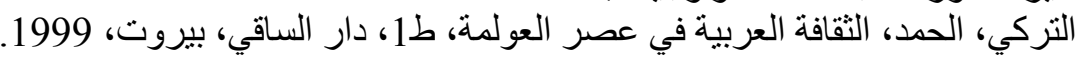

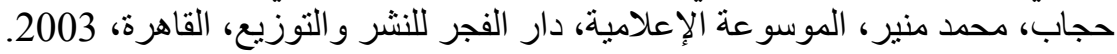
حنفي، حسن، الثقافة العربية بين العولمة و الخصوصية، الاعلة، الفية الفكر السياسي العددان (4 و 5 5).

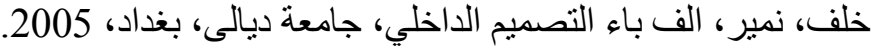

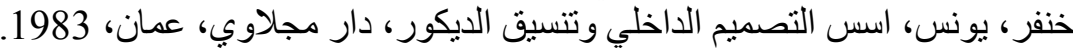

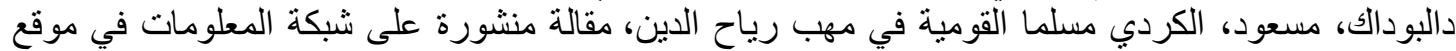

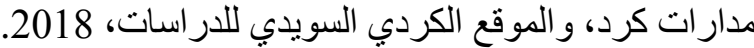

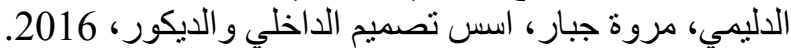

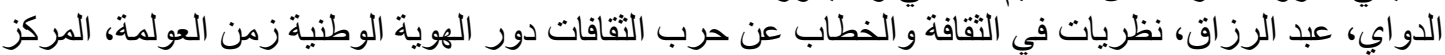

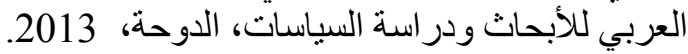

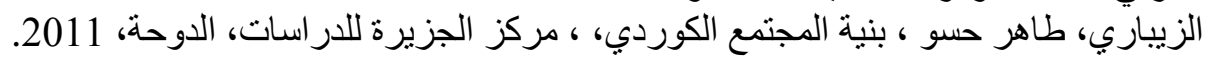

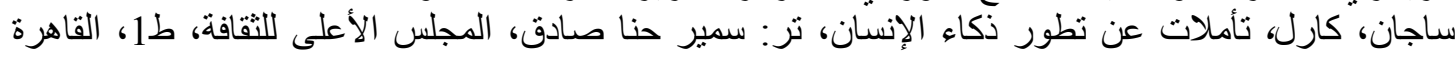




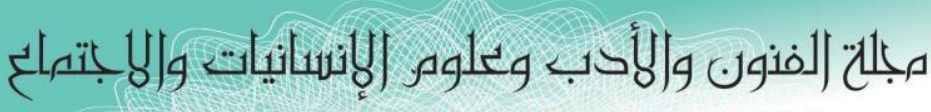

Journal of Arts, Literature, Humanities and Social Sciences

ISSN online: 2414 - 3383

ISSN print: 2616 - 3810

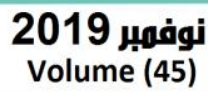

(45) (40)

November 2019

سليمان، رسمية عبد القادر، المجتمع العربي بين التمسك بالهوية و الإدماج العالمي، ط1، المركز العالم للار اسات و أبحاث الكتاب الأخضر ، ليبيا، 2006.

السندي، ديدرخان، المجتمع الكردي في المنظور الاستشر اقي، دار اراس للنشر، اربيل، اقليم كردستان العراق،

2008

شالين، جان، الإنسان نشوؤه وارتقاؤه، تر : صادق قسومة، طاء 1ا، بتر ا، دمشق،

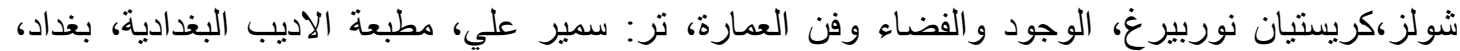

شيرز اد، شيرين احسان، الحركات المعمارية الحديثة: الاسلوب العالمي في العمارة، المؤسسة العربية للدر اسات

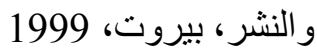

عبد المجيد، حنان محمد، التغير الاجتماعي في الفكر الإسلامي الحديث، المعهد العالي للفكر الإسلامي، فرجينيا

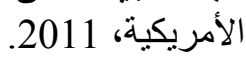

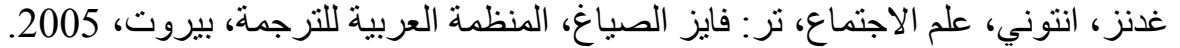

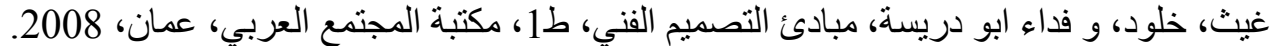
الفران، هاني خليل، الهمية دور التصميم الداخلي في نعزيز النية، الهوية الثقافية العربية للحيز الدئية الداخلي، مجلة العمارة و الفنون، العدد 14، مبروك، سناء، الهوية والإنتماء الإجتماعي في شمال سيناء، المركز القومي للبحوث الإجتماعبة والجنائية،

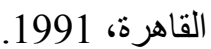

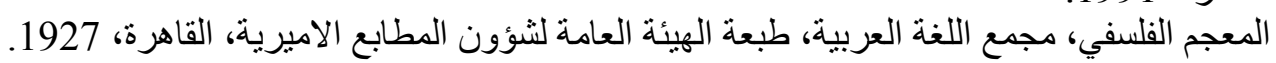

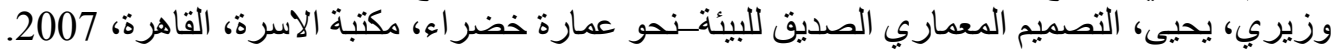

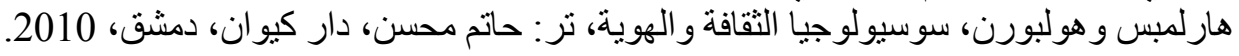

\section{References}

1. Ibrahim, Mustafa et al., Intermediate Dictionary, vol. 1, Islamic Library, Istanbul, without year printed.

2. Abugad, Hassan Ezzat, Visual phenomena and interior design, Dar Al-Ahad AlBohtari, Beirut, 1971.

3. Abu Zarour, Rawand, The Effect of Interior Design on the Success of the Content of Interior and Exterior Architectural Space - Separate Residential Buildings (Villas) in Nablus as a Model, Unpublished Master Thesis, An-Najah University, Nablus, 2013.

4. Bahamam, Ali Bin Salim et al., A Guide to Affordable Housing, Prepared by Prince Abdullah Institute for Research and Consulting Studies, Saudi Arabia, 2004.

5. Al-Bayati, Namir Qasem Khalaf, AB Interior Design, University of Diyala, Iraq, 2005.

6. Al-Bayati, Namir Qasim, Rules and Concepts in Interior Design, Central Printing Press, Diyala University, 2012.

7. Python, Rana Mumtaz Dawood, Architectural Sustainability - Strategies of Simulating Nature and Architectural Form, Unpublished Master Thesis, University of Technology, Baghdad, 2006. 


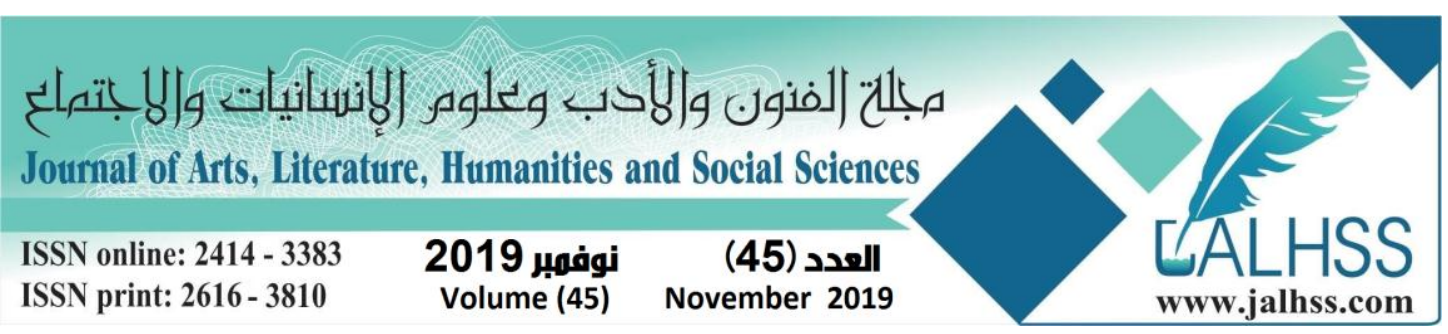

8. Al-Turki, Al-Hamad, Arab Culture in the Era of Globalization, 1st edition, Dar Al-Saqi, Beirut, 1999.

9. Hegab, Mohamed Mounir, Media Encyclopedia, Dar El Fagr for Publishing and Distribution, Cairo, 2003.

10. Hanafi, Hassan, Arab culture between globalization and privacy, political thought Nos. 4 and 5.

11. Khalaf, Numair, AB Interior Design, University of Diyala, Baghdad, 2005.

12. Khanfar, Younis, Foundations of Interior Design and Decoration, Dar Majlawi, Amman, 1983.

13. Dalbodak, Masoud, Kurdish Muslim nationalist blown into the winds of religion, an article posted on the information network at the Madarat Kurd website, and the Swedish Kurdish website for studies, 2018.

14. Dulaimi, Marwa Jabbar, Foundations of Interior Design and Decoration, 2016.

15. Dawai, Abdul Razzaq, Theories in Culture and Discourse on the War of Cultures The Role of National Identity in the Globalization Period, Arab Center for Research and Policy Studies, Doha, 2013.

16. Al-Zibari, Taher Hasso, Structure of Kurdish Society, Al-Jazeera Center for Studies, Doha, 2011.

17. Sagan, Karl, Reflections on the Evolution of Human Intelligence, Tr .: Samir Hanna Sadek, Supreme Council of Culture, 1 st, Cairo, 2005.

18. Suleiman, Official Abdul Qader, The Arab Society Between Adherence to Identity and Global Integration, I 1, World Center for Green Book Studies and Research, Libya, 2006.

19. Sindi, D. Badrakhan, Kurdish Society in the Orientalist Perspective, Aras Publishing House, Erbil, Kurdistan Region of Iraq, 2008.

20. Shalin, Jean, Human Development and Evolution, Tr: Sadeq Qassoumeh, Petra, Damascus, 2005.

21. Schulz, Christian Norberg, Existence, Space, and Architecture, Tr .: Samir Ali, Al-Adib Baghdad Press, Baghdad, 1996.

22. Sherzad, Sherine Ihsan, Modern Architectural Movements: The International Style in Architecture, Arab Foundation for Studies and Publishing, Beirut, 1999

23. Abdul Majeed, Hanan Mohammed, Social Change in Modern Islamic Thought, Higher Institute of Islamic Thought, Virginia, 2011.

24. Godens, Anthony, Sociology, TR: Fayez Sayagh, Arab Organization for Translation, Beirut, 2005.

25. Ghaith, Kholoud, and Fida Abu Dreisah, Principles of Art Design, Arab Society Library, Amman, 2008.

26. Al-Farran, Hani Khalil, The Importance of the Role of Interior Design in Promoting the Arab Cultural Identity of the Interior Space, Journal of Architecture and Arts, No. 14, 2019.

27. Mabrouk, Sana, Identity and Social Affiliation in North Sinai, National Center for Social and Criminal Research, Cairo, 1991.

28. The Philosophical Dictionary, The Arabic Language Academy, Public Authority for Amiri Printing Press, Cairo, 1927. 


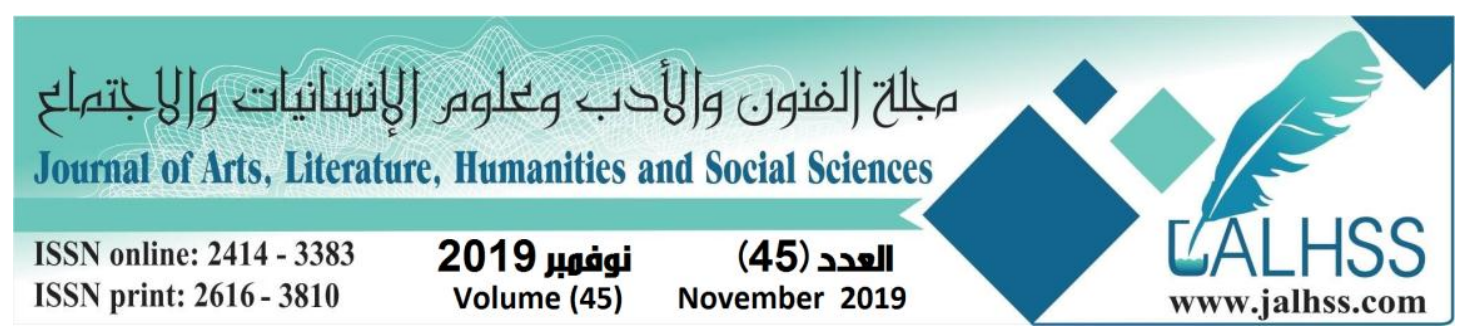

29. Waziri, Yahya, Environmentally Friendly Architectural Design - Towards Green Building, Family Library, Cairo, 2007.

30. Harlemps and Holborn, Sociology of Culture and Identity, Tr .: Hatem Mohsen, Dar Kiwan, Damascus, 2010.

31. Ayalp, N., "Cultural Identity and Place Identity in House Environment: Traditional Turkish House Interiors" WSEAS International Conference on Art and Culture Montreux, 2014.

32. Ching Francis, Interior design Illustrated, Van Nostrand Reinhold Company, N.Y, 1987.

33. Clapham, J. C., The Meaning of Housing, A Pathways Approach, The Policy Press, Bristol, 2005.

34. Goodland, Robert \& Herman Daly, Environmental Sustainability: Universal and Non-Negotiable, Ecological Applications, Vol.6,Issue.4, Wiley Online Library, 1996.

35. IFI, International Federation of Interior Architects Designer. IFI Interiors Declaration retrieved 10 May 2013

36. Mahgoub, Yasser, Sustainable Architecture In The United Arab Emirates, CAAIIA International Conference On Urbanism \& Housing,GOA, India, October, 1997.

37. Wester-Herbe, M., Review Underlinying concerns in land - use conflicts- the role of place-identity, in Wester-Herb, 2005.

38. Manenti, C., International Conference on Green Buildings and Sustainable Cities, Sustainability and place identity, Procedia Engineering, 2011.

39. http://impr.com

40. http://sustainable design.com

41. Sustainable community profile, 1995 